\title{
Cash or Coupons? Testing the Impacts of Cash versus Vouchers in the Democratic Republic of Congo
}

\section{Jenny Aker}

\begin{abstract}
Despite the increased use of conditional and unconditional cash-transfer programs worldwide, a majority of social protection programs in both developed and developing countries use in-kind transfers and vouchers. This paper reports the results of a randomized evaluation of an unconditional cash transfer and voucher program in the Democratic Republic of Congo, a country that has been plagued by intense civil war for much of the past two decades. In response to the devastating conflict, a number of international organizations have used cash and vouchers to assist internally displaced populations. While the value of the voucher was less than the household's normal total food expenditures (infra-marginal), voucher households purchased more food items than they would have otherwise had they been provided with cash (extra-marginal). There was also no evidence that cash-transfer households were using their transfers for temptation goods. The differences in purchases did not lead to differential improvements in food security, household coping strategies, or asset ownership between the two groups. However, cash-transfer households were able to save a portion of their transfer, and the cash-transfer program was more cost effective for the implementing agency. These results suggest that unconditional cash transfers can be a more efficient means of improving outcomes for extremely vulnerable populations, even in failed states. However, access to markets for goods and services is a necessary precondition for cash-transfer programs to succeed.
\end{abstract}

JEL Codes: J22, O12, C21

Keywords: cash transfers, in-kind transfers, consumption, Democratic Republic of Congo, impact evaluation. 


\section{Cash or Coupons? \\ Testing the Impacts of Cash versus Vouchers in the Democratic Republic of Congo}

Jenny Aker

Tufts University

Jenny C. Aker, Department of Economics and The Fletcher School, Tufts University, 160 Packard Avenue, Medford, MA 02155; Jenny.Aker@tufts. edu. We thank Concern Worldwide in DRC for their support in all stages of this project and would especially like to thank Feargal O'Connell, Gabrielle Smith, Julia Lewis, Kai Matturi, Saul Butters, Joel Tschite and the data collection team in DRC. We greatly appreciate comments from participants at the seminar at the University of Gottingen, the Northeastern Universities Development Conference (NEUDC) and Clark University. We are grateful for financial support from UNICEF and Tufts University. All errors are our own.

CGD is grateful for contributions from the UK Department for International Development and the William and Flora Hewlett Foundation in support of this work.

Jenny Aker. 2013. "Cash or Coupons? Testing the Impacts of Cash versus Vouchers in the Democratic Republic of Congo.” CGD Working Paper 320. Washington, DC: Center for Global Development.

http://www.cgdev.org/publication/cash-or-coupons

Center for Global Development 1800 Massachusetts Ave., NW Washington, DC 20036

202.416.4000

(f) 202.416 .4050

www.cgdev.org
The Center for Global Development is an independent, nonprofit policy research organization dedicated to reducing global poverty and inequality and to making globalization work for the poor. Use and dissemination of this Working Paper is encouraged; however, reproduced copies may not be used for commercial purposes. Further usage is permitted under the terms of the Creative Commons License.

The views expressed in CGD Working Papers are those of the authors and should not be attributed to the board of directors or funders of the Center for Global Development. 


\section{Contents}

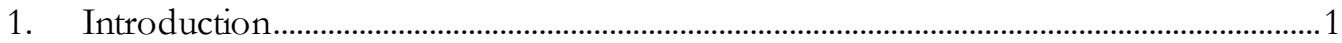

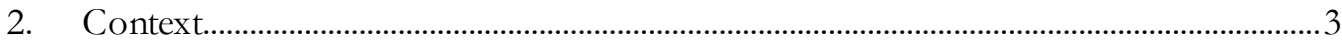

2.1. Conflict and internally displaced populations in eastern DRC ................................ 3

2.2. The Context in Eastern DRC......................................................................................

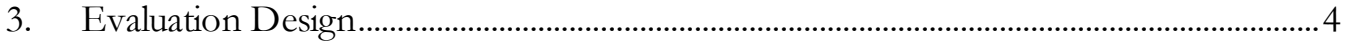

3.1. Transfer Modalities ....................................................................................................

3.2. Targeting and Randomization.....................................................................................

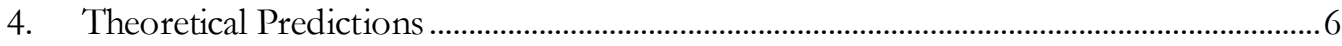

4.1. Demand and Welfare under Cash and In-Kind Transfers........................................6

4.2. Why use vouchers in eastern DRC? .....................................................................

5. Data and Empirical Strategy...............................................................................................

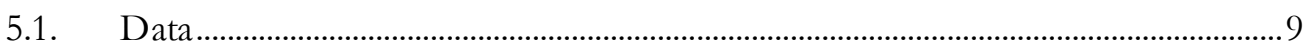

5.2. Pre-Program Balance of Program Recipients ............................................................10

5.3. Estimation Strategy ………………………………............................................11

6. Results: Uses of the Transfer .......................................................................................12

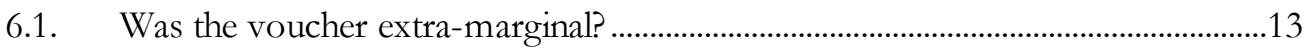

6.2. Was the voucher binding? ............................................................................................14

7. Results: Effects on Other Measures of Well-Being ..............................................................16

7.1. Food Security …………………………………………………………………………..16

7.2. Income, Assets and Coping Strategies ..........................................................................16

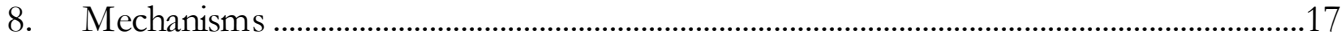

8.1. Why did voucher and cash households make different purchases? ........................17

8.2. Why was well-being the same in voucher and cash households?...........................19

9. Ruling Out Alternative Explanations....................................................................................

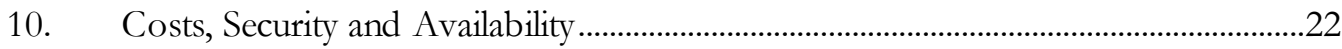

10.1. What were the costs of the transfer modalities to the implementing agency?....23

10.2. What were the costs of the cash and voucher program for program recipients? 23

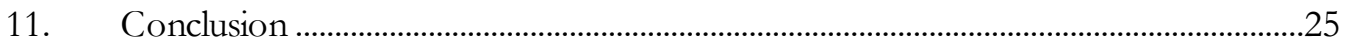

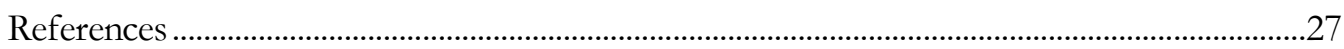





\section{Introduction}

How should wealth be redistributed to the poor? Despite the fact that cash transfer programs have become an increasingly important part of social protection programs worldwide, a majority of w elfare transfers in both developed and developing countries are still in-kind (Tabor 2002, Currie and Gahvari 2008). For example, President Obama's 2013 budget allocated over $\$ 293$ billion to "food and nutrition" programs (food stamps), Medicaid and housing assistance (including vouchers), suggesting that the current ratio of U.S. in-kind assistance to cash transfers is 5.6 to 1 (Glaeser 2012). Given that economic theory predicts that a program recipient will at least (weakly) prefer a cash transfer as compared with an equal-valued in-kind transfer, why would the public sector prefer in-kind transfers?

There are several reasons why in-kind transfers might be preferred to cash. First, governmental or non-governmental organizations might want to encourage program recipients to consume particular food or non-food items, which is more difficult with unconditional cash transfers (Cunha 2012, Currie and Gahvari 2008). Second, in-kind transfers may encourage the non-poor to self-select out of welfare programs, thereby assisting in targeting the poor (Nichols and Zeckhauser 1982, Moffitt 1983). Third, if certain items are not readily available on local markets, in-kind transfers (such as food and medicines) can increase local supply and households' access to such items. Fourth, in-kind transfers may be more politically practicable than cash transfers, especially to populations who are not eligible for the program (De Janvry, Fargeix, and Sadoulet 1991; Epple and Romano 1996). And finally, providing in-kind transfers could be less risky for program recipients, especially if cash is easier to steal.

Despite the widespread use of both cash and in-kind transfers in developing countries, the empirical evidence on the relative merits of each modality is primarily limited to developed countries and for the US food stamp program (Whitmore 2002, Hoynes and Schazenbach 2009, Fraker, Martini and Ohls 1995). While there is some evidence of the impacts of cash versus in-kind transfers (food distributions) in Mexico (Cunha 2012, Skoufias et al 2008), there are few studies assessing the impact of cash versus in-kind transfers in developing countries, especially in sub-Saharan Africa. ${ }^{2}$

\footnotetext{
${ }^{1}$ In the economics literature, vouchers are categorized as in-kind transfers, as they are often restricted to the purchase of particular items and can lead to a kinked budget constraint (Whitmore 2002, Currie and Gahvari 2008). In the humanitarian field, donors, implementing agencies and policymakers often make a distinction betw een cash transfers, in-kind transfers (free distributions) and vouchers, as vouchers are more fungible than pure in-kind distributions. For this reason, we do not explicitly refer to vouchers as in-kind transfers throughout this paper, although our motivation and analysis of the voucher program treats them as such.

${ }^{2}$ The International Food Policy Research Institute (IFPRI) is w orking with the World Food Program (WFP) to assess the impact of cash and in-kind transfers, including food distributions. Two of these evaluations are in sub-Saharan Africa (Hoddinott, Sandstrom and Upton 2013).
} 
We report the results of an income support program in the Democratic Republic of Congo (DRC), where households were randomly assigned to different transfer modalities. The primary objective of the program was to improve access to food and basic non-food items (NFIs) among internally displaced persons (IDPs) living in an informal camp. The first intervention, an unconditional cash transfer, was provided in three distributions over a sixmonth period. The second intervention, an equal-valued voucher, was a coupon that could be redeemed at an organized "voucher fair" selling a variety of agricultural, food and nonfood items, and was restricted only to food items in the second and third transfers. Given the extreme vulnerability of the target populations, there was no pure comparison group. Thus, while we are unable to measure the overall impact of the transfer, we are able to measure the relative impact of these two transfer modalities on household purchases, consumption and savings.

Our primary data are household-level surveys conducted with 252 households before, during and immediately after the program. We supplement these data with price data collected throughout the program period, administrative data from the primary cooperative distributing the cash transfer and monitoring data collected during the closed fairs where items were sold to voucher recipients.

Economic theory predicts that an individual will be (weakly) better off if given cash as compared with an in-kind transfer or vouchers. Following the thought experiment outlined in Whitmore (2002), suppose that a program recipient is provided with US $\$ 130$ in food "coupons", as is the case in our program. If the program recipient would have spent more than US $\$ 130$ on food, then she will treat the food voucher just like cash (called "inframarginal" or "underprovided") and utility will be the same under both modalities. If, how ever, the program recipient would have spent less than US\$130 on food, then the food vouchers will cause her to spend more on food so that she can use the full value of the voucher (called "extra-marginal" or "overprovided"). In other words, the vouchers will cause the program recipient to shift her expenses tow ards more food items and reach a lower indifference curve as compared with the cash transfer program recipient, resulting in a deadweight loss to program recipients (Whitmore 2002).

In an effort to test this theory, our main outcomes focus on the uses of the cash transfer and vouchers, as well as measures of household well-being. Our first main finding is that the transfer modality affected the uses of the transfer. While the voucher transfer was inframarginal for some households, it was extra-marginal for particular food items, namely salt, fish and rice. Cash transfer households were able to use their transfer for a more diverse set of food and non-food items, including health expenses, school fees and debt reimbursement.

Our second main outcome is that the different transfer modalities did not have strong differential impacts on household well-being. While there were no differences in household food security, asset accumulation or income, cash households were more likely to save a portion of their transfer (as related to voucher households), worth approximately USD $\$ 1.50$, equivalent to a week of household income. This suggests that, despite the changes in 
purchasing behavior of voucher transfer recipients, the transfers were (somewhat) nonbinding.

We next turn to understanding the potential mechanisms behind these effects. We consider five dimensions: timing and location of the transfer, timing and location of purchases, interhousehold sharing, voucher sales and intra-household bargaining power. There were strong differences in the timing and location of cash and voucher households' purchases, as well as some evidence of savings among cash households. In addition, both types of households shared a portion of their transfer, and a few voucher households exchanged their voucher for cash. Overall, these results suggest that the logistics of the voucher program constrained households' choices, thereby affecting their purchasing decisions. Voucher households were willing to forfeit up to 50 percent of the value of their transfer to obtain cash, suggesting that resale was not costless.

The cash transfer program was also strongly cost-effective, with lower per recipient costs as compared with the voucher program. Nevertheless, leakage and program recipients' costs of obtaining the transfer were similar in both groups.

Our results contribute to the literature on cash versus voucher transfers in developing countries. A more recent strand of literature has investigated the effectiveness of conditional and unconditional cash transfer programs (Baird, McIntosh and Ozler 2011). What is less well understood is whether cash or in-kind transfers, including vouchers, will yield differential improvements in well-being. Cunha (2012) has measured these relative effects of the PAL program in Mexico, finding substantial overprovision of some food items and limited effects on nutritional status. Our unique set-up allows us to directly observe the quantity demanded under two transfer modalities that are equivalently-valued, and to understand the mechanisms behind these results in a context that is relevant for many international organizations.

The rest of the paper proceeds as follows. Section 2 describes the context in DRC and the history of welfare transfers in the country. Section 3 describes the experimental design and Section 4 outlines the theoretical framework. Section 5 describes the different datasets and estimation strategy. We discuss the results in terms of uses of the transfer (Section 6) and other outcomes (Section 7) before discussing mechanisms (Section 8) and alternative explanations (Section 9). We describe the cost-benefit analysis in Section 10 before we conclude.

\section{Context}

\subsection{Conflict and internally displaced populations in eastern DRC}

One of the largest countries in sub-Saharan Africa, the Democratic Republic of Congo has been at the center of what has been termed "Africa's world war" since the late 1990s. An original five-year conflict pitted government forces, supported by Angola, Namibia and 
Zimbabwe, against rebels backed by Uganda and Rwanda. The war has claimed an estimated three million lives, either as a direct result of fighting or because of disease and malnutrition.

Despite a peace deal in 2003, renewed fighting erupted in the eastern parts of the country in 2008, displacing millions of people. As of 2011, it was estimated that there were 1.7 million

IDPs in the eastern part of the country. The most vulnerable regions are those of North and South Kivu, which are subject to attacks by government and militia forces, looting and sexual violence. IDPs have been forced to move to formal or informal camps. A map of the program area is provided in Figure 1.

\subsection{The Context in Eastern DRC}

Without access to land, livestock or other means of generating income, IDPs are often heavily dependent upon external aid to meet their basic needs. Throughout the conflict, international and non-governmental organizations have typically distributed food aid, medicines, agricultural inputs and non-food items. More recently, such organizations have also provided cash transfers and vouchers, the latter of which is a type of coupon that enables program recipients to purchase goods at pre-organized fairs. In an effort to increase the incomes of conflict-affected households and enable them to access basic food and nonfood items, Concern Worldwide, the partner in this study, has been implementing three types of programs in the Masisi Territory since 2008: 1) a voucher program, where program recipients were provided with vouchers to spend at organized voucher fairs, providing access to non-food items (NFIs), as well as foodstuffs, agricultural inputs and primary school fees; 2) a cash-for-work (CFW) program, primarily focusing on road rehabilitation in areas less affected by the conflict; and 3) seeds and tools distributions.

The focus on vouchers as a component of humanitarian assistance in Masisi is not uncommon. Of more than 15 international organizations working in eastern DRC, over 10 of them provide voucher assistance. The preference for vouchers (as compared with cash transfers) has primarily been due to security concerns in conflict-affected areas, as well efforts to discourage spending on "temptation goods" (i.e., spending on items such as alcohol).

\section{Evaluation Design}

\subsection{Transfer Modalities}

As part of its 2011/2012 humanitarian response program in eastern DRC, Concern Worldwide designed a program that sought to increase households' access to basic food and non-food items and services by providing income transfers to approximately 474 households 
in an informal IDP camp. The bulk of the transfers were provided between September and November, the "hunger months". ${ }^{3}$

The first intervention was the cash transfer (cash), whereby households received an unconditional cash transfer of US $\$ 130$ over a seven-month period. The total value of the transfer was approximately $2 / 3$ of the total annual GDP per capita for DRC. Payments were made in three disbursements: September 2011 (US\$90); November 2011 (US\$20) and February 2012 (US\$20). The transfer was directly deposited into an interest-free account at the office of a local cooperative located in the regional market center (Masisi Center). The accounts were opened free of charge, and there were no fees to withdraw the cash transfer. Households could save their cash in the account if they wished. Program recipients had to travel to this market center to receive the cash transfer.

The second intervention, a voucher, provided program recipients with coupons to spend on any items included for sale at pre-organized voucher fairs. The total value of the voucher program was also US $\$ 130$ over three distributions, with similar timing to the cash transfers. For the first distribution (US\$90), program recipients could spend the voucher on a wide variety of food and non-food items at the fair. The fair included 122 vendors and four primary schools in the area, and provided access to traditional non-food items (NFIs), household items, clothing, school fees, agricultural inputs and small animals. ${ }^{4}$ The second and third vouchers could be spent only on food items at voucher fairs, whereby program recipients circulated freely among pre-approved vendors. ${ }^{5}$ All of the voucher fairs took place in the regional market center (Masisi Center) on a pre-arranged non-market day. The maximum prices for each item at the fair were set at the same prices in the previous market in Masisi Center.

The two interventions were equivalently-valued and distributed at the same time and location, but differed in their transfer modality. Thus, comparing outcomes under the different interventions will allow us to determine whether the two transfer modalities affected costs and other measures of household well-being. In particular, comparing

\footnotetext{
${ }^{3}$ Masisi Territory has a bimodal rainfall system, with rains between September and December (and a harvest in January and March) and a second rainy season between March and May (with a harvest in June through August). Thus, the first transfers coincided with a "hungry period", the period between harvests, when supply might be relatively lower and prices relatively higher, especially for IDPs with limited access to their own agricultural land (Save the Children 2003).

${ }^{4} \mathrm{~A}$ full list of items available at the multisectoral fair is available upon request. As no vendors were willing to sell plastic sheeting or mosquito nets, Concern purchased and sold these items at the fair. Program recipients could purchase school fees for either the entire year or on a semester basis.

${ }^{5}$ Eleven food vendors were eligible to participate at the second food voucher fair, and vendors were unwilling to provide palm oil. For this reason, Concern purchased and sold palm oil at local prices at the second food voucher fair. Additional items on the second food fair included sugar, cassava flour, beans, rice, vegetable oil, dried fish and salt. The third food voucher fair included 18 food vendors and the same food items, in addition to potatoes and peanuts. A comparison of the item availability and discussions with program recipients revealed that almost all items were available at the fair, with the exception of meat and doughnuts.
} 
outcomes between the voucher and cash groups will allow us to measure the differential effect of the voucher program as compared with the cash transfer.

An ideal experiment would have also included a group without access to any transfer support. Due to the humanitarian nature of the intervention and the extreme vulnerability of IDPs in this context, it would have been unethical to assign households to a comparison group (no transfer). Hence, while we can estimate the impacts of alternative transfer modalities, we are limited in our ability to estimate the overall impact of the social protection program.

\subsection{Targeting and Randomization}

The program targeted 474 internally displaced households in one informal camp in the Masisi territory of DRC, with a total population of 2,500 individuals. All households residing in the camp were eligible for the intervention. In all, 237 households were randomly assigned to the cash transfer intervention and 237 were randomly assigned to the voucher intervention. The cash transfer or voucher was primarily provided to the female household member (either the head of household or the spouse of the household head). ${ }^{6}$ The study timeline is presented in Figure 2.

As we could not carry out the randomization at the neighborhood level and there was no minimum buffer zone between households, spillovers are a key threat to the identification strategy. We will partially address this in later sections.

\section{Theoretical Predictions}

\subsection{Demand and Welfare under Cash and In-Kind Transfers}

Although all households received equivalently valued transfers during the same period, the transfer modality (cash or voucher) might have differential effects on household demand. If the value of the transfer is infra-marginal, then the marginal effect of the in-kind transfer would be no different from the effect of the cash transfer (Southworth 1945, Cunha 2012).7 If, how ever, the value of the transfer is extra-marginal, and assuming no resale is possible, then the effect of the voucher program on household demand is likely to be different from the effect of the cash transfer, since the voucher constrains the program recipient to purchase more food items as compared with the cash transfer (particularly for the last two transfers).

More formally, assume that households have preferences over two composite goods, food and non-food items, and maximize a utility function $U$ over both goods. Non-food items in

\footnotetext{
${ }^{6}$ In the voucher group, 95 percent of program recipients were w omen (226 households out of 237). For the cash group, 91 percent of program recipients were women (215 out of 237).

${ }^{7}$ The theoretical model underlying the impact of the cash or in-kind transfers (to which we extend vouchers) on consumption was originally developed by Southworth (1945).
} 
this context include clothing, health and education expenditures, as well as a range of durable and non-durable assets. We assume that the utility function is strictly increasing and concave in both arguments. Pre-transfer, the household has income $Y$ and each set of composite goods has fixed prices $p_{\mathrm{NF}}$ and $p_{\text {F}}$. Solving the first-order conditions implies that the consumer will maximize utility subject to his or her budget constraint, at points $A$ or $B$ in Figure 3 (Currie and Gahvari 2008, Cunha 2012).

A lump sum cash transfer of $T$ will cause a parallel shift out of the pre-transfer budget line. If both goods are normal goods, then the unconditional cash transfer will increase demand for both food and non-food items for each type of consumer. How ever, an equivalentlyvalued voucher that can only be spent on food items will lead to a kinked budget constraint. Whether the household is indifferent between or prefers the cash transfer to the voucher depends upon the type of household. The infra-marginal household (Household B) will reach the same indifference curve regardless of the transfer type, so the household is indifferent between cash and in-kind transfers. If frictionless resale is not possible, then extra-marginal households (Household $A$ ) are strictly better off under the cash transfer, as they can reach a higher indifference curve. In other words, the household would prefer to consume at $A^{\prime}$, but is constrained to $A^{\prime \prime} .{ }^{8}$ The voucher is therefore infra-marginal for Household $B$ (and thus equivalent to cash), and extra-marginal for Household $A$. The distortionary effect of the voucher for these households is the difference in the quantity of food items purchased under the voucher scheme, as compared with what would have been purchased under a cash transfer regime for the same household (Cunha 2012).

A transfer is non-binding if a household consumes less of the good than it purchased (Cunha 2012). If resale is allowed, this will shift up the kink in the budget constraint and allow households to reach a higher indifference curve. If households are unable to sell the goods purchased, then the voucher is binding for the household. However, this does not necessarily imply that the goods will be allocated equally within the household. ${ }^{9}$

This simple model therefore yields three predictions:

1) The quantity demanded of food and non-food items will be the same under equivalently-valued cash transfers and vouchers if the value of the voucher is inframarginal

2) The quantity demanded of food items will be higher with vouchers than equivalently-valued cash transfers if the voucher is extra-marginal, primarily for the last two transfers

\footnotetext{
${ }^{8}$ The extra-marginality is defined with respect to the post-cash transfer budget (rather than the pre-transfer budget), as a cash transfer may change the demand for the in-kind good (Cunha 2012).

${ }^{9}$ This model can be extended to cases to cases where a voucher (or in-kind transfer) can purchase multiple goods (Cunha 2012) to show that households will substitute tow ards complements of extra-marginal and binding voucher food transfers, thereby mitigating the individual welfare loss.
} 
3) If the transfer is binding, and no resale is possible, then household welfare is maximized for extra-marginal households under the cash transfer regime.

However, the relative impacts of each transfer modality on other measures of well-being are ambiguous, especially when goods are substitutable with items that cannot be purchased under the voucher regime.

\subsection{Why use vouchers in eastern DRC?}

The simple theoretical model suggests that, if the voucher is extra-marginal, then food items will be "overprovided" under the voucher regime. Why would this modality be preferred in eastern DRC?

Despite the potential distortionary effect on purchases, providing in-kind transfers, including vouchers, may be good public policy in some contexts (Whitmore 2002), especially in fragile states. First, a government or donor might prefer that individuals consume more of particular goods than they would if given the choice, often called "paternalism" (Currie and Gahvari 2008, Cunha 2012). While a paternalistic motivation might come at the expense of individual preferences, it could potentially lead to increased consumption of those goods and thereby lead to improvements in other indicators of well-being (such nutritional status). While the preference for purchasing particular food and non-food items seems to have been less of a priority among donors and implementing agencies in eastern DRC, ${ }^{10}$ previous studies cited concerns about the consumption of "temptation" goods associated with cash transfers (ODI 2009).

Second, voucher transfers could potentially improve the targeting of such programs, especially if governments or implementing agencies are unable to accurately target the poor. If the voucher increases the cost of participation enough to deter the non-poor from applying, or provides a good that is not valued by the non-poor, then this can induce the non-poor to self-select out of social protection programs (Nichols and Zeckhauser 1982, Moffitt 1983). Yet since many of the programs in eastern DRC target IDPs, who are relatively easy to identify, this would not appear to be a major justification for the program.

Third, in-kind transfers and vouchers may simply be more politically feasible than cash transfers, especially for those who will not be targeted by the program (De Janvry, Fargeix, and Sadoulet 1991; Epple and Romano 1996). In the context of eastern DRC, this would involve the host communities. If host communities are not provided with the same type of assistance as IDPs, then providing IDPs with vouchers might be more acceptable to host communities. Since the support of these communities is necessary to establish and sustain IDPs, this could be an important concern.

\footnotetext{
${ }^{10}$ Many agencies switched from a pure in-kind transfer (the distribution of food and non-food items) to vouchers in an effort to provide a greater choice to program recipients (UNICEF 2012). http://www.unicef.org/infobycountry/drcongo_56433.html
} 
Fourth, voucher transfers may facilitate a pecuniary redistribution of wealth. For pure inkind transfers (ie, distributions), an increase in the supply of the publicly-provided good can lower its market price (Coate, Johnson, and Zeckhauser 1994). The analogy in the DRC context is one of market integration: If transaction costs are high, local prices of food and non-food items can be prohibitively high in particular markets. Vouchers could potentially lower transaction costs by organizing "voucher fairs" for vendors, thereby ensuring a certain demand for vendors who would normally be unwilling to risk traveling to more remote markets.

A final potential rationale for the use of in-kind transfers is one of security, theft and leakage. In terms of leakage, there is widespread evidence of corruption in social protection programs (Olken 2007), which could be arguably be greater for cash as compared with in-kind transfers or vouchers. In terms of security, in the context of conflict, cash program recipients could potentially be targeted by armed militia or looters. Vouchers, on the other hand, do not have any market value outside of the fair, and so could potentially limit the likelihood of theft or leakage by non-recipients or armed groups.

\section{Data and Empirical Strategy}

\subsection{Data}

This paper uses five primary datasets. The first dataset is a household survey of 252 households in the camp. The baseline survey was conducted in September 2011, with followup surveys in November 2011 and March 2012. While attrition was significant in November 2011 due to armed conflict in the area, the research team located over 94 percent of households for the final survey. There was no differential attrition between the treatments either in November 2011 or March 2012.

The household survey included modules on household demographics, asset ow nership, shocks, income-generating activities and food security. For the follow-up surveys, we also included modules on the uses of the cash transfer or voucher. As the surveys were conducted during a humanitarian crisis, we were mindful of the time burden on respondents. As a result, the household surveys did not include a full income and expenditure module, but rather collected data on specific expenditures (such as clothing), asset accumulation (as a wealth proxy), food security (dietary recall) and the uses of the transfers. ${ }^{11}$

The second dataset are a set of exit surveys at each voucher fair with specific questions on the ways in which program recipients spent their vouchers. This complements the household

\footnotetext{
${ }^{11}$ The household diet diversity score (HDDS) is a 24-hour recall measure of diet diversity. The measure interviews the person responsible for preparing meals within the household and lists 12 different food categories, including grains, tubers, beans, fruits, vegetables, meat, fish, eggs, oils, sugar and condiments. The indicator ranges from 0 to 12, with 12 the highest degree of diet diversity. USAID/FANTA. 2006. Household Dietary Diversity Score (HDDS) for Measurement of Housebold Food Access: Indicator Guide, Version 2.
} 
recall data on the uses of the transfers, and provides specific information on the day of the transfer, the prices paid and the availability of goods.

The third dataset is price data for over 25 products in the primary market in the area (Masisi Center) between September 2011 and March 2012. These data are used to assess the price effects of each modality, as well as the value of the assets owned by households.

The fourth dataset is the account information provided by the Cooperative Bwira, to which the cash transfer was deposited. The dataset includes information on the date of the transfer, the day of the receipt of the transfer, the amount withdrawn and any savings. These data are used to measure the timing and use of the savings accounts.

Finally, Concern Worldwide and Tufts University collected qualitative data during focus groups with men, women, market resource persons, school principals and the camp administration in March 2012. These data are used to provide some insights into the quantitative findings.

\subsection{Pre-Program Balance of Program Recipients}

Table 1 shows the summary statistics for key variables in the sample. The average household size in the camp is 5.5 , and 42 percent of households are female-headed. Approximately 50 percent of respondents had some type of education, and almost 90 percent had been born in the Masisi territory and living in the camp for more than one year.

Turning to assets and income, households have very few income-generating opportunities, relying upon 2.8 sources of income. Of these, most households rely upon external daily wage labor, either in agriculture or as day laborers (ie, many women worked as transporters of agricultural products to and from markets). Very few households work in commerce (6\%), artisanal activities $(6 \%)$, agriculture $(6 \%)$, forestry $(6 \%)$ or migration $(2 \%)$. Overall, this suggests that households in the camp are highly dependent upon the external informal labor markets to ensure their livelihoods.

The degree of poverty among camp residents is also evident when looking at the portion of income spent on food in the past week: households spent over 75 percent of their weekly expenditures on food..$^{12}$ This is well above the threshold for food poverty in developing countries, which classifies households that spend more than 50 percent of their income on food as extremely poor (Fisher 1997). Using the household diet diversity score (HDDS), average household diet diversity among both cash and voucher households was 2.90 (out of a total of 12 food categories). This is well below the average HDDS in sub-Saharan Africa

\footnotetext{
${ }^{12}$ The value of food expenditures before the program was $1815 \mathrm{FC}$, or US $\$ 2$ per week. If food expenditures remain relatively constant over the course of the program, households would have spent US $\$ 50$ on food. This suggests that the value of the income transfer could have been extra-marginal (for most program recipients), but could have been infra-marginal for the wealthiest households (for example, the maximum amount spent on food prior to the program was $48000 \mathrm{FC}$, or \$USD 48).
} 
(4) and the recommended HDDS (6). Households and children only ate 1.29 meals in the past 24 hours.

Table 2 shows the balance of observable characteristics between and the cash and voucher households prior to the program. Overall, the results suggests that the randomization was successful in creating comparable groups along observable dimensions. Differences in preprogram household characteristics are small and insignificant. In general, the cash program recipients were more likely to be born in the Masisi territory and were living in the camp for longer than a year, the former of which is statistically significant. As these variables could potentially proxy for greater social netw orks within the camp, we control for this covariate in our regression results. We also provide some additional information on the place of birth to better understand the distance between the camp and the respondent's home village.

\subsection{Estimation Strategy}

To estimate the potential differential effects of different transfer modalities on a variety of outcomes, we use a simple reduced form regression specification comparing outcomes using pooled data from the November and March rounds. This takes the following form:

$$
Y_{i}=\gamma+\operatorname{acash}_{i}+\mathbf{X}^{\prime} \gamma \gamma+\theta_{N}+\varepsilon_{i}
$$

The variable $Y_{i}$ represents the outcome of interest (uses of the transfer, purchases, food expenditures, food security and assets) of household $i$ over the course of the program. cash $_{\mathrm{i}}$ is an indicator variable equal to one if the household received an unconditional cash transfer, 0 if the household received the voucher. $\theta_{\mathrm{N}}$ are neighborhood fixed effects within the camp, the level at which we stratified the randomization. To improve precision, we include a vector of household baseline covariates, $\mathbf{X}_{i \nu 0}^{\prime}$, such as place of birth. ${ }^{13}$ The error term consists of $\varepsilon_{i}$, which captures unobserved individual or household characteristics or idiosyncratic shocks. We correct for heteroskedasticity when there is a binary dependent variable. The coefficient of interest is $a$, the impact of the cash transfer (as compared with the voucher) on a variety of outcomes, under the assumption that $c a s h_{i}$ is orthogonal to $\varepsilon_{i}$. When data are available for two post periods, we pool the data and include a linear time trend variable.

Since households were randomly assigned to the cash or voucher intervention, observable and unobservable characteristics should be similar prior to the program. Nevertheless, there are several threats to our identification strategy. First, randomization occurred at the household level within the same camp, and it was not possible to ensure a minimum distance between cash and voucher households. For this reason, it is likely that there are spillovers between the two groups. For example, cash households could have shared part of their cash transfer with voucher households, thereby allowing households to decrease their consumption of food items and increase their consumption of temptation goods. Similarly,

\footnotetext{
${ }^{13} \mathrm{We}$ also control for household size in all regressions as a robustness check and find that all results are robust to the inclusion of this variable.
} 
voucher households could have shared part of their goods with cash households, thereby increasing their consumption of food items and reducing their consumption of temptation goods. ${ }^{14}$

A second concern is differential attrition. During the second round of the survey, violence intensified in the area, and more than half of the households fled into the surrounding hills. If the types of households who stayed were different from those who were displaced, potentially by being more vulnerable, this could affect the external validity of the findings. Or, if the characteristics of the remaining households differed between the voucher and cash groups, then any observed differences between the two interventions could be due to those differences, rather than the different transfer modalities. We therefore test whether the baseline characteristics of attriters are different between the two groups. We also estimate the effect of the program using only the March data, rather than the November data, when the rate of attrition was less than 6 percent.

A final threat to the estimation strategy is differential take-up. For example, if the cash transfer made it easier for corrupt agents to steal the transfer, then compliance would be differential between the cash and voucher households. Or, if households felt more stigmatized by participating in a voucher program (as compared with the cash transfer program), they might have refused assistance. ${ }^{15}$ While the latter scenario seems unlikely in this context, we address these issues in Section 9.

\section{Results: Uses of the Transfer}

This section provides the results of the empirics along three main dimensions. First, we compare food and non-food expenditures between cash and voucher households to better understand whether the total value of the voucher was infra- or extra-marginal. We then compare the purchasing decisions of cash transfer versus voucher households in order to understand whether the transfer was extra-marginal for particular items. We also measure the quantity of goods purchased by cash transfer households to better understand whether the extent of extra-marginality for particular items. Finally, we compare the purchasing decisions with consumption in voucher households in order to determine whether the voucher was binding.

\footnotetext{
${ }^{14}$ The threat of spillovers was less likely to affect household purchasing decisions, especially for cash households, as voucher households could not share their vouchers with other households at the fair. While cash households could have shared some of their cash with voucher households (thereby affecting their purchasing decisions), this would have made it more difficult for us to detect differences in demand betw een the two groups.

${ }^{15}$ Imperfect compliance in this context was minimal. First, adverse stigma effects associated with participation

(as in Moffitt (1983)) are unlikely in this context where all households in the camp were provided with some type of assistance. Second, households were required to present beneficiary identification cards to receiv e aid packages and program recipients had to travel to Masisi Center to receive the cash or voucher, making it unlikely that ineligible households in fact received aid.
} 


\subsection{Was the voucher extra-marginal?}

In terms of total food expenditures, the vouchers are infra-marginal for approximately 50 percent of households (Figure 4). ${ }^{16}$ In other words, with a voucher transfer equal in value to about 2400 FC per week (USD \$2.62) for the last two transfers (which could only be spent on food items), about 50 percent of households consume more than this amount on a weekly basis. This comparison assumes that weekly household food expenditures are relatively constant over time, and that preferences are time-consistent. While these assumptions might not be valid in this context, it provides a benchmark of comparison for understanding the potential extra- or infra-marginality of the cash transfer.

Looking at individual food items, however, there appears to be considerable over-provision. As the cash transfer was unconditional, program recipients were free to spend the cash transfer how they wished. Overall cash households used their transfer to purchase 6.54 different categories of goods, including staple grains $(79 \%)$, other grains $(60 \%)$, beans $(43 \%)$, meat (66\%), oil (77\%), condiments (38\%), salt (77\%), fish (47\%), health expenses $(7 \%)$, school fees $(70 \%)$ and debt reimbursement (31\%). (Respondents could list more than one use of the cash transfer, so the total can exceed 100\%.) Fewer than 1 percent of households used the cash transfer to buy "temptation goods", defined in this context as doughnuts and beer. Thus, cash transfer recipients primarily used the transfer to ensure immediate consumption needs, but also to invest in particular non-food items and children's education.

Table 3 shows the different uses of the transfer by transfer modality, with a graphical representation in Figure 5.17 Overall, the results paint a picture of more diverse uses of the transfer by cash households, with significant overprovision of particular food items for voucher households. Cash households purchased 2.53 more types of food and non-food items as compared with the voucher group. Cash program recipients were significantly more likely to purchase staple grains (such as corn), condiments, beans, oil, meat condiments and vegetables as compared to those households in the voucher group (Panel A). All of these differences are statistically significant at the 1 percent level. These households were also more likely to use the transfer to pay for school fees and medical expenses, as well as to reimburse debts, with a statistically significant difference. The patterns are similar when looking at only the second (Figure A1) and third transfers (Figure A2), when we would expect greater differences between the two groups.

\footnotetext{
${ }^{16}$ The same is true when looking at expenditures on both food and non-food items (Figure A1) and controlling for household size.

${ }^{17}$ A potential concern with this measure is that program recipients could simply list the first (or largest) expenditures made after receiving the transfer, which could differ by treatment groups. Thus, we might see a treatment effect on measured expenditures rather than actual expenditures. This concern is alleviated by the way in which the question was measured; after program recipients answ ered the initial categories, enumerators were instructed to go through a comprehensive list of potential categories and ask the recipient if they spent the cash transfer or voucher on that particular category.
} 
While cash transfer households were more likely to purchase a more diverse set of items, there are some items that the voucher households were more likely to purchase. Among food items (Panel A), voucher households were 13 percentage points more likely to purchase other grains (namely rice) and 16 percentage points more likely to purchase salt, with a statistically significant difference at the 1 percent level. ${ }^{18}$ These differences were relatively stronger for the second and third transfers, when the voucher could only be used on food items. In addition, voucher households were 40 percentage points more likely to purchase fish during the second transfer, with a statistically significant difference between the two. These results suggest that certain food items, namely rice, fish and salt, were overprovided to voucher households.

While Table 3 shows the extensive margin of overprovision for each food item, we might be interested in the intensive margin of overprovision. Given potential measurement error related to the amounts purchased for earlier transfers, we only collected data on the amount spent for the most recent transfer (i.e., the second transfer in November 2011 and the third transfer in March 2012) and for specific categories (i.e., those that were easily able to quantify, such as grains or oils).

Figure 6 shows the extent of overprovision for particular food items, namely salt, rice and fish. Similar to the methodology used by Cunha (2012), the curves in Figure 6 are the empirical cumulative distribution functions ( $\mathrm{CDF}$ ) of the quantities purchased by posttransfer cash (dashed lines) and voucher households (solid curves). For cash households consuming less than voucher households, the vertical distance between the cash and voucher households shows the extra-marginality of each item (Cunha 2012). Many cash households did not purchase these food items, even after receiving a large cash transfer. For example, 65 and 52 percent of cash households did not purchase any salt or dried fish, respectively. While salt is overprovided for all voucher households who purchased it, fish is only overprovided at larger quantities, and the overprovision of rice is unclear. This is shown more formally in Table 4, which shows the average quantity of overprovision for each of these food items. ${ }^{19}$ On average, voucher households purchased an additional $10 \mathrm{~kg}$ of salt, $.34 \mathrm{~kg}$ of rice and 1.5 fish as compared with the cash households, with a statistically significant difference.

\subsection{Was the voucher binding?}

If one of the objectives of the voucher program was to encourage consumption of food items (as compared with temptation goods), these benefits would be mitigated to the extent

\footnotetext{
${ }^{18}$ Voucher households were also more likely to purchase agricultural inputs (including seeds) than cash households, but this was only for the first transfer.

${ }^{19}$ Table 4 shows that household food expenditures did not statistically differ between the two transfer modalities, suggesting that the voucher was infra-marginal for total food expenditures. These results are robust to controlling for household size and using the per capita household food expenditures.
} 
that households do not consume what was provided, in other words, the voucher was nonbinding. ${ }^{20}$

Table 5 (Panel A) provides some evidence of the extent to which the voucher was binding by assessing whether the purchased items were consumed by recipient households. The table shows the differential effects of the transfer modality on household diet diversity, as measured by dietary recall over the previous 24 hours. While households in the camp increased their diet diversity between September and November (from 2.9 food groups in September to 3.36 food groups in November, a 15-percent increase), diet diversity fell again between November and March to lower than baseline levels (2.71). This suggests that there are strong seasonal differences in household diet diversity, although perhaps not necessarily in a way that would be consistent with typical agricultural households.

Overall, there were no statistically significant differences in diet diversity between the cash and voucher households, and the consumption of almost all of the food items was similar between the two groups. This is the case for the overprovided food items, namely grains, fish and salt (a condiment), as well as those items more commonly purchased by cash households (such as meat). The only statistically significant difference in consumption was for eggs, which was 2 percentage points higher in cash households. These results were similar for the November and March surveys.

Why were these food items not consumed at the household level? Since the data were collected three weeks after each transfer, it is difficult to separate between resale, storage or lumpy consumption. While lumpy consumption might be possible with rice and fish, this is highly unlikely with salt, as the quantities purchased were substantial (ie, 25-kg bags). This suggests that the voucher was not fully binding, and were either stored or resold by voucher households. Based upon survey data, the latter of these explanations seems to be the most likely.

Taken together, the results in Tables 3 and 4 suggest that the voucher program distorted household purchases along both the extensive and intensive margin, encouraging households to purchase more salt, rice and fish as compared with cash transfer households. However, these distortions did not lead to differential consumption, suggesting that the in-kind transfer was non-binding. Before delving into the mechanisms that explain our findings, the next section presents some evidence as to whether the transfer modalities had differential effects on well-being.

\footnotetext{
${ }^{20}$ Resale of the goods would detract from the objective of increasing the consumption of those specific foods, whereas lumpy purchases supports this objective, if those purchases are oriented tow ards consumption.
} 


\section{Results: Effects on Other Measures of Well-Being}

\subsection{Food Security}

While the voucher was extra-marginal for some food items, and not fully binding, a natural question is whether the transfer modality had differential effects on household well-being, as measured by food security, income, asset ow nership and household coping strategies. Panel B of Table 5 presents the results of equation (1) for a variety of food security measures, including the number of meals per day and the number of months of adequate food provisioning, a subjective measure of food security status. Overall, the number of meals per day (for the household and children) increased significantly between the baseline and follow up period for both groups, and the likelihood of suffering from food insecurity decreased. In the absence of a pure comparison group, we cannot provide a causal interpretation to this trend, as these changes could be due to seasonal fluctuations. Nevertheless, there is no statistically significant difference by the two transfer modalities. While cash transfer households reported that they were 10 percentage points less likely to suffer from food insecurity than voucher households, there was not a statistically significant difference between the two.

\subsection{Income, Assets and Coping Strategies}

The voucher transfer distorted households' purchases, primarily by purchasing more salt, fish, and grains. While this did not lead to changes in food security status, it could have led to differential changes in well-being along other dimensions. For example, if voucher households incurred significant costs from the resale of their salt, they would have earned less income than cash households and thereby had less to invest in food and non-food items. Yet if voucher households were able to earn significant profits from the sale of salt, they might have been able to earn higher incomes, invest more and better cope with idiosyncratic shocks.

Table 6 shows the differential effects of the program on differential indicators of w ell-being, namely, income and asset ow nership, livestock ow nership and coping strategies. While these indicators in general improved over the course of the program, there were no differential effects of the transfer modality on income, income sources or asset and livestock ownership (Panel A). The two exceptions are in the area of savings and coping strategies. Cash households were 9 percentage points more likely to have savings left over from the transfer (as compared with only 1 percent of voucher households), and were able to save USD \$1.50 more than voucher households - approximately half of weekly household income. These results were statistically significant at the 1 percent level (Panel A).

In light of the differential effects of the program on savings, this could have also affected households' ability to cope with shocks. Over $86 \%$ of households in the Bushani camp suffered at least one shock betw een September and March, primarily illness (54\%), the death of a household member ( $9 \%$ ), increased local prices (19\%) and conflict (57\%). Households used a variety of different coping strategies to deal with these shocks, including changing 
their diet (reducing diet diversity), increasing income via short-term strategies (such as migration, working as a day laborer, selling off assets or taking children out of school) and rationing food within the household (such as reducing the number of meals per day). Overall, both cash and voucher households decreased their use of these coping strategies between September 2011 and March 2012, with similar patterns for the cash and voucher households. The two exceptions were migration and selling off household assets: as compared with voucher households, cash households were more likely to send a household member to migrate, but less likely to sell off assets. These differences are statistically significant between the two groups. ${ }^{21}$

\section{Mechanisms}

One of the core results in this paper is that receiving a voucher transfer, as compared with an unconditional cash transfer, led to the overprovision of certain food items. This did not lead to differential improvements in food security or other dimensions of well-being between the cash and voucher households, but did allow some cash households to save a portion of their transfer. Why is this the case? This section presents evidence on the channels through which the observed impacts on both purchasing decisions and outcomes occurred, using both household surveys and focus group research.

\subsection{Why did voucher and cash households make different purchases? \\ 8.1.1. Did the voucher transfer affect the timing and location of purchases?}

Concern Worldwide worked hard to ensure that most food and non-food items were available on the fairs (including agricultural inputs, livestock and school fees), and tried to identify program recipients' preferences before holding the fair. Despite these efforts, some items were simply not available (such as meat, doughnuts or land) or were only available in limited quantities. Thus, by the design of the voucher program, voucher program recipients had to purchase different items (especially for the last two transfers), as certain items were simply not offered at the fair. At the same time, the availability of items was not the only reason for these differences.

\footnotetext{
${ }^{21}$ Comparing different coping strategies weights each strategy equally. How ever, some coping strategies can be "harmless and reversible", whereas others are "harmful and reversible." To take these differences into account, we construct a coping strategy index (CSI) to account for different severity and frequency of different coping strategies (Maxwell and Caldwell 2008). We also calculate a modified CSI using a subset of universally used coping strategies (reducing food quality, borrowing money for food and reducing the number of meals per day). Using a range from 0 (least severe) to 11 (most severe), the average CSI was 2.54 for all households in September 2011, before the start of the program. The CSI dropped significantly for both cash and voucher households between September, November and March, from 2.54 to .75, confirming that households were using fewer (and less severe) coping strategies. The same pattern was observed using the "universal" CSI (comprised of three less severe coping strategies). These differences between the two groups were not statistically significant.
} 
One of the key ways in which voucher transfers might alter purchases was through the timing and location of purchases. For example, while cash transfer households could spend the transfer where, how and when they wished, voucher households had to use the voucher on the day of the fair, and for specific food items.

Table 7 shows the differential effects of the transfer modality on the location and timing of the transfer. Perhaps unsurprisingly, almost all of the voucher households used their transfer at the voucher fairs, while none of the cash transfer households did so (Panel A). Among cash transfer households, a majority used the transfer at a market outside of the camp, either at Masisi Center (approximately $20 \mathrm{~km}$ aw ay from the camp, and the same location as the voucher fairs) or the Nyabiondo market (approximately $2 \mathrm{~km}$ from the camp, in an area with greater insecurity). Cash households were also 3 percentage points more likely to use their transfer at a school than the voucher households, since voucher households could only pay for school fees with the first voucher. With the exception of school fees, all of these differences are statistically significant at the 1 percent level.

In terms of the timing of the transfer, none of the voucher households used their transfer over multiple periods, as part of the design of the voucher program (Panel B). By contrast, 75 percent of cash households used the transfer over multiple periods, allowing them to use the transfer how they wished. This also enabled cash transfer households to save a part of their transfer, although very few of these households saved at the cooperative account.

The fact that voucher households had to spend their transfer all at once, on one market, also affected what households purchased. Given the distance between the camp and the fair, voucher households could not purchase heavy items without arranging transport, as they did not have the opportunity to purchase these items at a closer market (or make several trips, given the distance between the camp and the fairs).22 During focus group discussions with program recipients, they stated that weight was often a consideration in deciding what to purchase. In an effort to use their voucher on the given day and purchase what they wanted, 65 percent of voucher recipients traveled with family members to the voucher fair in order to aid in transporting newly-purchased items. Those who were unable to travel with family members who could share the burden purchased fewer items (ie, only one box of salt rather than two) or lighter, smaller items which they could carry without paying for transport. As one voucher program participant mentioned, "If something was too heavy, I didn't buy it...I wanted to buy two boxes of salt but could only carry one, so I bought one plus other things."

\subsubsection{Did the voucher transfer affect intra-household decision- making?}

As the transfer program primarily targeted women within the household (over 93\% of program recipients were women), the program could have affected household outcomes by

\footnotetext{
${ }^{22}$ Transport cost 5-6.000 FC per trip.
} 
changing intra-household dynamics or women's control over resources, particularly related to purchasing decisions.

While there are no data on intra-household decision-making before the program, data on different indicators of intra-household dynamics were collected in November 2011 and March 2012. Overall, a high percentage of female program recipients in cash households $(94 \%)$ reported that they were responsible for spending the cash transfer or voucher, either alone $(6 \%)$ or jointly (Table 7 , Panel C). In those cases where spending decisions were taken jointly, the program recipient provided part of the transfer to her husband or son. These figures were similar among voucher households, without a statistically significant difference between the two groups. More than $85 \%$ of program recipients discussed how to use the income support with their spouse, and almost all of the female program recipients were implicated in the decision on how to spend the transfer. None of these decisions were statistically different in the cash and voucher households. Thus, it does not appear as if the transfer modality affected intra-household decision-making with respect to the uses of the transfer.

\subsection{Why was well-being the same in voucher and cash households?}

Despite the fact that the voucher transfer led to different purchasing decisions between voucher and cash households, there were few differences in household well-being, with the exception of savings. Why is this the case? The most common explanation is that the vouchers and cash transfers were non-binding; ie, voucher households could sell the goods that they purchased or share some of these goods with other households, whereas cash households could share some of their cash. Alternatively, if an underground market for vouchers existed, voucher recipients could have potentially sold their voucher at less than face value, leaving less income available for voucher households. And finally, while the transfer modality did not affect intra-household bargaining with respect to the uses of the transfer, it could have changed decision-making along other dimensions, thereby affecting welfare outcomes.

Table 8 provides some evidence of these different mechanisms. As expected, program recipients shared part of the transfer (Panel A): while cash households were more likely to share money with others ( $40 \%$ of cash households, as compared with $25 \%$ of voucher households), voucher households were more likely to share goods purchased with the transfer ( $46 \%$ of voucher households, as compared with $32 \%$ of cash households). These differences are statistically significant. While this figure combines the data from all three transfers, these sharing patterns were largely similar across the first two transfers and the last transfer. ${ }^{23}$ This suggests that sharing is an important household coping mechanism within the camp, and

\footnotetext{
${ }^{23}$ While inter-household sharing is an important part of coping strategies among many rural households, especially displaced populations without access to credit, savings or insurance, this sharing can also reduce the impact of the income transfer on program recipients.
} 
that program recipients shared primarily to reallocate funds to households with different needs. ${ }^{24}$

While the sale of vouchers was technically prohibited, some program recipients reported exchanging their voucher for cash, potentially resulting in a lower income transfer to the household. Although it is impossible to gauge the frequency with which this practice occurred, voucher recipients reported that they could exchange their \$USD 20 voucher for approximately $\$ 11.25$ - $\$ 14.15$ at the fair. This suggests that vouchers traded for about 55-70 percent of their face value. ${ }^{25}$ For those that traded in their vouchers, this meant that they had less income to spend on food and non-food items. This is partially supported by the data: While leakage was the same in voucher and cash households, cash households, on average, reported spending USD $\$ 5$ more than voucher households, with a statistically significant difference between the two (Table 8, Panel B).

A final potential explanation is one of intra-household decision-making. Men and women within cash households made joint decisions with respect to children's education, agriculture, inter-household sharing and savings; fewer than $1 / 3$ of cash households reported that the male household head made these decisions alone (Table 8, Panel C). ${ }^{26}$ Interestingly, males seemed to make decisions alone more frequently when it came to education and savings, as compared with agriculture and inter-household sharing. The structure of intra-household decision-making was similar for voucher households, and remained relatively constant between November and March.

This is similar when using an alternative measure of intra-household dynamics, namely, the amount of money allocated to women's, men's and children's clothing. Overall, cash households spent 20,125 FC (\$19-20) on clothing between November and March for all household members. Over 75 percent of this budget was spent on women and children's clothing, and the value of men's clothing was about half of the value of women's clothing.

\footnotetext{
${ }^{24}$ While average household size in the camp was 5.5 members, households ranged from 1 to 11 members. Since the size of the transfer was the same regardless of household size, this meant that some households received $\$ 110$ per capita, whereas others received $\$ 10$ per capita.

25 In particular, voucher recipients reported that they could exchange a voucher worth $18.400 \mathrm{FC}$ for 10.000-13.000 FCat the fair. One possible reason that vouchers traded at below their face value was that trading vouchers was technically prohibited, so that some buyers and sellers might have refrained from participating in the market. For those that did participate, search costs may have been high; while all buyers and sellers were together in the fair, program recipients had to find a willing buyer and arrange for a secure location to sell at the fair, which was difficult given monitoring. This was also exacerbated by the time frame, as the sale would have had to take place on the day of the fair. And finally, program recipients and traders might have been concerned about being caught; while recipients would not have been removed from the program, traders would have been prohibited from participating in future voucher fairs, a potentially lucrative business opportunity for them.

${ }^{26}$ This type of decision-making within the camp might differ from the decision-making structure within program recipients' home villages. Program recipients reported that decision-making was "harder" within the camp, as they didn't have the support of their broader extended family network.
} 
Similar patterns were observed among voucher households, and none of these differences are statistically significant between the two groups.

Overall, the results in Table 8 provide support for the fact that the voucher was nonbinding, as households could sell or share the goods purchased with that voucher. While not conclusive, this suggests a possible mechanism as to why we did not observe differences in well-being along most dimensions, with the except of cash savings.

\section{Ruling Out Alternative Explanations}

There are several threats to the validity of the above findings. First, it might have been easier for cooperative agents to extract the cash transfer from those households, resulting in differential take-up between the cash and voucher groups. Second, the different transfer modalities could have affected attrition across both groups. For example, since cash households were able to spend their transfer how they wished, including medical expenses, this could have reduced the likelihood of illness or death within the cash households.

The results in Table 9 suggest that none of these factors were driving the results. In particular, two findings are of note. All households received all of their transfers, regardless of the modality. Households received 99,807 FC, less than the reported amount, but this was equal across the two groups. It is unclear whether the difference in reported versus actual amounts was due to measurement error or leakage in the program, although there was no differential leakage (Panel A). Similarly, while attrition was significant in the November round (over 54 percent), it was 6 percent in the final round, without a statistically significant difference between the two groups.

A second alternative explanation to the interpretation of the above findings is the potential differential effects of the transfer modality on prices. If the cash transfer put greater inflationary pressure on local markets as compared with the voucher, this could have reduced the value of the cash transfer for those households and decreased the differences in the likelihood of purchasing particular food or non-food items. Or, if voucher households were faced with higher prices on the voucher fairs, particularly if traders exerted some degree of market power, then this could have reduced the purchasing power of voucher households.

While we have data on the prices for various foodstuffs at the primary market in the area, as well as on the voucher fairs, we do not have detailed price data for all markets in the area, and in particular immediately before and after the cash transfer program. Yet the overall magnitude of the cash transfer program in the area was fairly small, with a target of 500 households and US $\$ 30,000$ over a seven-month period, as compared with an IDP population of 60,000. In addition, cash households spread out their purchases over time and space, purchasing goods on three different markets that were over 15-20 km apart, with fairly limited integration between these markets. This suggests that the impact of the cash transfer on local inflation was negligible. 
In terms of prices on the voucher fairs, Concern Worldwide collected price data on the key regional market prior to the voucher fair and used these prices as the maximum prices for goods at voucher fairs. While this might have affected program recipients' ability to bargain for a lower price, it is unlikely that voucher households faced substantially higher prices than cash households in the same market. Nevertheless, since voucher households did not have a choice to travel to other markets, this constrained their choice and ability to allocate their transfer in an optimal way. ${ }^{27}$

The identifying assumption fails if, because of spillovers, the cash transfer group is not a proper counterfactual for how households in the voucher group would have behaved if they were provided with the cash transfer. This might be the case if, for instance, households in the voucher group changed their behavior as a result of knowing that other households had been offered cash (or vice versa), or cash households shared some of their transfer with the voucher households. An optimal research design to would have conducted the randomization at the camp level. Absent these possibilities, a second-best option would have randomized at the camp neighborhood level, ensuring a minimum distance between neighborhoods (or households within the neighborhood). While all of these designs were considered and discussed by the research team and Concern Worldwide, there were insufficient sampling units, as well as concerns that a neighborhood-level randomization might be construed as "targeting" certain households within the camp.

Since we cannot rule out the likelihood of spillovers between the two groups - and in fact, evidence points to inter-household sharing - we will try to address these concerns in future research in two ways. First, we will provide empirical evidence on the likelihood of interhousehold sharing of both groups, as is outlined below. And second, we will exploit the inter-neighborhood variation in the intensity of treatment in order to compare voucher and cash households in high and low intensity areas. Finally, it is important to note that the likelihood of sharing would have resulted in few er differences between the two groups, which we did not observe in purchasing decisions.

\section{Costs, Security and Availability}

One of the key reasons for using vouchers in eastern DRC is potential risks to the implementing agency and program recipients. Yet the previous results suggest that cash households were able to purchase what they needed. Given these results, what were the costs of the program to the implementing agency and to the program recipients themselves?

\footnotetext{
${ }^{27}$ While prices on the voucher fairs were comparable with those on the Masisi Centre market for that week and monitored activity during the fairs -- very few markets have a "law of one price". Voucher program recipients noted that traders were unwilling to negotiate for items and often cited the maximum price on the market rather than bargaining. For example, program recipients cited that vegetable oil cost 5.500 FC at the voucher fair but 4.500 FC on the Masisi market, whereas salt cost 9.000 FC at the fair and 8.500 FC at the Masisi center market, a difference of US\$.50.
} 


\subsection{What were the costs of the transfer modalities to the implementing agency?}

Figure 7 shows the costs of each transfer modality (cash or voucher) per program recipient. These costs include the staff time (for developing the vouchers, implementing the voucher fairs, planning the cash distributions and security); materials (printing of vouchers, fair site materials and other printing materials); and security, travel and account and transfer fees (primarily for the cash transfer). The total costs for designing and implementing the voucher program were more expensive than the cash program. ${ }^{28}$ When looking at the costs per program recipient, the voucher program cost USD $\$ 14.35$ (per recipient), whereas the cash program cost USD $\$ 11.34$ (per recipient), about USD $\$ 3$ cheaper per program recipient. Overall, the cost breakdown shows that staff time represents the largest percentage of costs for both interventions, followed by transport and voucher printing (for the voucher intervention) and account-opening fees (for the cash intervention). Yet since the accountopening fees are a one-time, fixed cost, if Concern were to continue cash transfers with existing beneficiaries, the cost per cash program recipient would have only been $\$ 6$-- or $\$ 8$ less expensive per program recipient.

\subsection{What were the costs of the cash and voucher program for program recipients?}

While the cash transfer program was less expensive for the implementing agency, an important question is whether the two transfer modalities were similar in terms of their costs to program recipients. For both the cash and voucher program, program recipients had to travel $20 \mathrm{~km}$ to obtain their transfer, a significant time cost for program recipients (over three hours). While the travel time was similar for both, there are two additional considerations for program recipients: waiting time (for registration and distribution) and security.

In theory, cash transfer recipients were able to obtain their cash from the cooperative during certain days or times, thereby spreading out the number of program recipients on a particular day. For the first cash transfer, all program recipients arrived at the cooperative at the same time, meaning that many program recipients had to wait the entire day. For the second and third transfers, program recipients were scheduled for certain time blocks, which significantly reduced the waiting time. The average waiting time was 1 hour and 45 minutes, with less than $25 \%$ of program recipients waiting more than three hours (Concern 2011). If transfers were provided over longer periods, or program recipients did not need them urgently, in theory, the waiting time could have been reduced even further.

While cash recipients could have travelled to the cooperative at different times, voucher recipients had to first wait in line for their vouchers (primarily for verification). For the first

\footnotetext{
${ }^{28}$ Even if the number of voucher recipients were doubled (from 237 to 500 ), the cost per voucher program recipient would be about the same as the cost per cash program recipient.
} 
multisectoral fair, the average waiting time was 2 hours, with 30 percent of program recipients waiting for more than 3 hours. For the last two voucher fairs, the waiting time was closer to 1 hour and 30 minutes. Thus, the waiting and travel time was similar for both cash and voucher program recipients, and none of the recipients mentioned this as an issue either during the voucher exit fairs, the cash transfer monitoring report, the surveys or the focus group discussions.

A final cost when comparing the cash and voucher program, especially in a highly insecure environment such as eastern DRC, is one of security. For example, even if cash transfers are preferred to vouchers in terms of costs, benefits and program recipients' preferences, a voucher program might offer greater security to the implementing agency and program recipients. ${ }^{29}$

In general, there are several key issues to consider when comparing the security of transfer modalities, including the observability of the transfer, the location of the transfer distribution and the location and transport of purchases. For example, if non-program recipients can easily observe a certain transfer modality, then this could make program recipients easier targets for thieves or looters. Or, if a certain transfer modality requires longer travel or wait times to distribute the transfer, or requires grouping large number of program recipients to distribute the transfer, this could put program recipients at greater risk, especially if they are in an insecure location.

In terms of observability, both cash and vouchers are easy to hide, and cash program recipients reported that it was easy to conceal the cash while traveling or within the camp. ${ }^{30}$ How ever, since voucher recipients had to use their voucher at the voucher fair, and then transport these goods back to the camp, voucher program recipients could have been easier to identify - and therefore at potentially greater risk - when traveling from the voucher fair to the camp.

In terms of the location of the transfer distribution, both the cash and vouchers were distributed at the same location, requiring a three-hour walk from the camp. As previously mentioned, the waiting time for both types of transfer modalities was relatively similar, so both program recipients experienced similar levels of risk. However, in theory, cash program recipients could travel to the cooperative when they chose; if this had been spread out over several days, then the waiting time would have been less. This would not have been possible with

\footnotetext{
${ }^{29}$ In addition to the security of program recipients, there is also the security related to the implementing agency. For cash transfer programs, implementing agencies often have one of two choices: 1) distributing the cash transfer themselves, whereby they assume most (if not all) of the risk, depending upon where the transfer is distributed; or 2) distributing the cash transfer via the private sector or a quasi-public party (such as a trader or cooperative). In the latter context, risk is transferred from the implementing agency to the distribution partner. In both cases, the amount of risk incurred by the program recipients depends upon where and how the cash is distributed, and what happens in the event of theft.

${ }^{30}$ It is also important to note that other CFW programs implemented in the area did not necessarily report higher levels of theft among CFW program recipients as compared with voucher recipients.
} 
the voucher program, how ever, as the vouchers needed to be spent in pre-arranged voucher fairs. The only way to reduce the wait time for the voucher program would be to issue vouchers that were redeemable for several days, at pre-arranged vendors, and spread out the registration process over a longer time period.

In terms of the location and transport of items purchased with the transfer, in this case, cash recipients were clearly at less risk, as they could choose when, where and how to purchase (and transport) their goods. This could be either within the camp, at nearby markets or at Masisi Centre. Cash recipients could also choose to make purchases on days with relatively greater security. Voucher recipients did not have this choice, by the design of the program, and therefore had to make purchases at Masisi Centre and transport them to the camp. Voucher recipients could have reduced this risk by potentially storing their goods at the Masisi market, and arranging for transport at a later time, but both of these options would have incurred additional costs.

All in all, these results suggest that the cash transfer program resulted in greater potential security to program recipients, with low er potential costs in terms of waiting time if households spread out the timing of seeking their transfer. This, combined with the fact that cash households had higher utility, suggests that the cash transfer program strongly dominates the voucher program in this context.

\section{Conclusion}

Redistribution to the poor through welfare transfers plays an important role in the economies of both developed and developing countries, especially those affected by conflict. This paper explores issues surrounding in-kind and cash transfers, using a randomized control trial of cash and vouchers in an internally displaced camp in eastern DRC.

Estimating program effects on household demand for both cash and voucher transfers, we find that some food items, namely salt, fish and rice, were largely extra-marginal (overprovided) for voucher households, meaning that voucher households were more likely to purchase these items than they would have under a cash transfer program. None of these extra-marginal transfers appeared to be binding, how ever, and so consumption (as measured by household diet diversity) was largely similar under the voucher and cash transfer modalities. In light of this, it is perhaps not surprising that there is no evidence of differential effects of cash and voucher transfers on income, assets or food security. However, the cash transfer did allow households to save some of their cash transfer.

Furthermore, households receiving cash did not appear to purchase "temptation" goods. While this could be in part due to reporting issues, it appears as if the cash was largely spent on food and non-food items, including items that invest in the short- and long-term wellbeing of households in DRC.

Some caution is required in terms of interpreting the external validity of these findings. First, while a variety of international organizations use in-king and voucher transfers, the design 
and implementation of voucher programs can differ substantially in terms of the values, conditions and eligibility. Second, as we cannot completely address the issue of spillovers, it is possible that the results might differ in contexts where inter-household sharing between voucher and cash recipients is unlikely. And finally, despite the conflict and high transaction costs in eastern DRC, both of which affect the extent of inter-market trade, traders appear to be willing and able to engage in spatial arbitrage, thereby ensuring that supply is available in local markets. This might not be the case in other complex emergencies. Despite these caveats, this research suggests that unconditional cash transfers may be successful in improving households' purchasing power in complex emergencies, while giving households the freedom of choice and at a lower cost. 


\section{References}

Ahmed, A., A. Quisumbing, and J. Hoddinott. 2007. "Relative efficacy of food and cash transfers in improving food security and livelihoods of the ultra-poor in Bangladesh," IFPRI Report submitted to the World Food Programme.

Angelucci, M. and G. De Giorgi. 2009. "Indirect Effects of an Aid Program: How do Cash Transfers Affect Ineligibles' Consumption?" American Economic Review, 99(1): 486508.

Attanasio, O. and A. Mesnard. 2005. "The impact of a conditional cash transfer programme on consumption in Colombia," The Institute for Fiscal Studies Report Summary: Familias 02.

Baird, Sarah, Craig McIntosh and Berk Ozler. 2011. "Cash or Condition? Evidence from a Randomized Cash Transfer Program." Quarterly Journal of Economics.

Caldés, N., D. Coady, and J. Maluccio. 2006. "The Cost of Poverty Alleviation Transfer Programs: A Comparative Analysis of Three Programs in Latin America," World Development, 34(5):818-37.

Coate, S., S. Johnson, and R. Zeckhauser. 1994. "Pecuniary redistribution through inkind programs," Journal of Public Economics, 55:19-40.

Cunha, J. 2012 "Testing Paternalism: Cash versus In-Kind Transfers." Unpublished mimeo.

Cunha, J., G.De Giorgi, and S. Jayachandran. 2011. "The Price Effects of Cash versus In-kind Transfers," NBER Working Paper, Number 17456.

Currie, J and F. Gahvari. 2008. "Transfers in Cash and In-Kind: Theory Meets the Data," Journal of Economic Literature, 46(2):333-383.

Daly, G. and F. Giertz. 1972. "Welfare Economics and Welfare Reform," American Economic Review, 62(1): 131-38.

De Janvry, A., A. Fargeix, and E. Sadoulet. 1991. "The Political Feasibility of Rural Poverty Reduction," Journal of Development Economics, 37(1-2): 351-67.

Deaton, A. S. 1981. "Theoretical and Empirical Approaches to Consumer Demand Under Rationing," In Essays in the Theory and Measurement of Consumer Behavior, in honour of Sir Richard Stone. Cambridge University Press, Ch. 3: 55-72.

Del Ninno, Carlo and Paul Dorosh. "Impacts of in-kind transfers on household food consumption: Evidence from targeted food programmes in Bangladesh." Journal of Development Studies, Volume: 40, Issue: 1 (2003).

Epple, D. and R. Romano. 1996. "Public Provision of Private Goods," Journal of Political Economy, 104(1): 57-84.

Fraker, T., A. Martini, and J. Ohls. 1995. "The Effect of Food Stamp Cashout on Food Expenditures: An Assessment of the Findings from Four Demonstrations," The Journal of Human Resources, 30(4): 633-49.

Garfinkel, I. 1973. “Is In-Kind Redistribution Efficient?” Quarterly Journal of Economics, 87(2): 320-30.

Gertler, P., S. Martinez, and M. Rubio-Codina. 2006. "Investing Cash Transfers to Raise Long-Term Living Standards," World Bank Policy Research Working Paper, No. 3994. 
Glaeser, Edward. “Cash Is Better Than Food Stamps in Helping Poor.” February 27, 2012. Bloomburg. http:/ / www.bloomberg.com/news/2012-02-28/cash-better-than-foodstamps-in-helping-poor-commentary-by-edward-glaeser.html.

Hoddinott, John, Susanna Sandstrom and Joanna Upton. 2013. "The impact of cash and food transfers: Evidence from a randomized intervention in Niger."

Hoynes, H. and D. Schanzenbach. 2009. "Consumption Responses to In-kind Transfers: Evidence from the Introduction of the Food Stamp Program," American Economic Journal: Applied Economics, 1(4): 109-39.

Islam, M. and J. Hoddinott. 2009. "Evidence of Intrahousehold Flypaper Effects from a Nutrition Intervention in Rural Guatemala," Economic Development and Cultural Change. 57(2): 215-48

Jacoby, H. 2002. "Is There an Intrahousehold 'Flypaper Effect'? Evidence from a School Feeding Programme," The Economic Journal, 112(476): 196-221.

Maxwell, Daniel and Richard Caldwell. 2008. The Coping Strategies Index: Field Methods Manual.

Moffitt, R. 1983. "An Economic Model of Welfare Stigma," American Economic Review, 73(5):1023-35.

Moffitt, R. 1989. "Estimating the Value of an In-Kind Transfer: The Case of Food Stamps," Econometrica, 57(2): 385-409.

Nichols, A. and R. Zeckhauser. 1982. "Targeting Transfers through Restrictions on Recipients," American Economic Review, 72(2):372-7.

Olken, Benjamin. 2007. "Monitoring Corruption: Evidence from a Field Experiment in Indonesia." Journal of Political Economy. Vol 115: No 2.

Overseas Development Institute (ODI). 2009. Concern Rubaya Cash Voucher Evaluation. Overseas Development Institute.

Sadoulet, E., A. de Janvry, and B. Davis. 2001. "Cash Transfer Programs with Income Multipliers: PROCAMPO in Mexico," World Development, 29(6): 1043-56.

Save the Children. 2003. Household Economy Analysis of the Rural Population of South-Western Bwito, Rutshuru, North Kivu, Democratic Republic of Congo. Save the Children: DRC.

Skoufias, E., M. Unar, and T. González-Cossío. 2008. "The Impacts of Cash and InKind Transfers on Consumption and Labor Supply," World Bank Policy Research Working Paper, No. 4778.

Southworth, H. 1945. "The Economics of Public Measures to Subsidize Food Consumption," Journal of Farm Economics, 27(1): 38-66.

Tabor, S. 2002. "Assisting the Poor with Cash: Design and Implementation of Social Transfer Programs," World Bank Social Protection Discussion Paper, No. 0223.

Tobin, J. and H. Houthakker. 1950. "The Effects of Rationing on Demand Elasticities," Review of Economic Studies, 18(3): 140-153.

Whitmore, D. 2002. "What Are Food Stamps Worth?" Princeton University Industrial Relations Section Working Paper No. 468. 
Figure 1. Map of Program Area

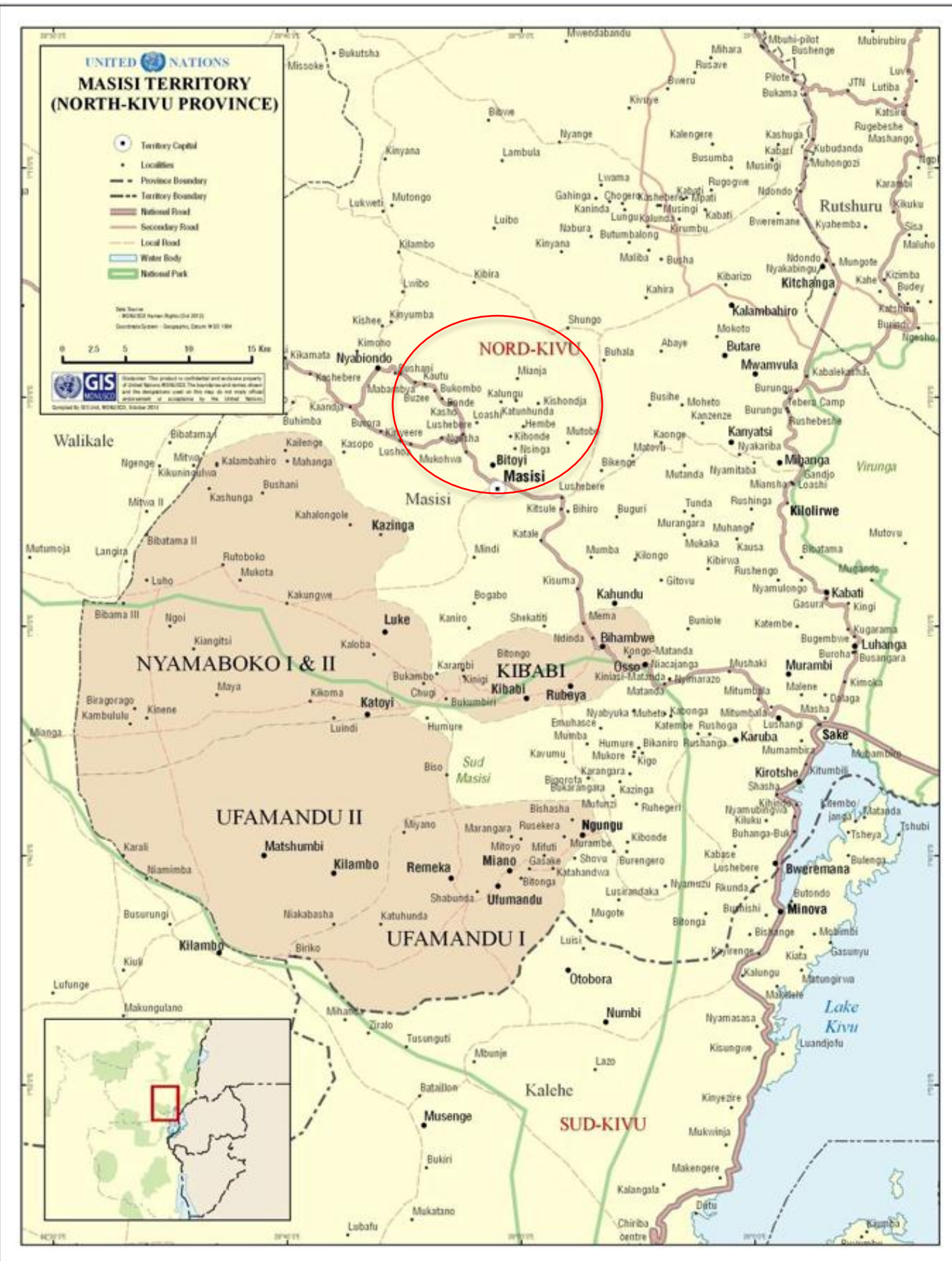


Figure 2. Timeline of Study and Data Collection Activities

\begin{tabular}{|c|c|c|c|c|c|c|c|c|c|c|c|c|}
\hline Year & January & February & March & April & May & June & July & August & September & October & November & December \\
\hline 2011 & & & & & & & $\begin{array}{l}\text { Write } \\
\text { proposal } \\
\text { and } \\
\text { design } \\
\text { research }\end{array}$ & $\begin{array}{l}\text { Identify } \\
\text { program } \\
\text { participants } \\
\text { and design } \\
\text { program }\end{array}$ & $\begin{array}{l}\text { Collect } \\
\text { baseline data } \\
\text { First cash } \\
\text { transfer and } \\
\text { voucher } \\
\text { distribution } \\
\text { (multisectoral } \\
\text { fair) }\end{array}$ & $\begin{array}{l}\text { Second } \\
\text { cash } \\
\text { transfer } \\
\text { and } \\
\text { voucher } \\
\text { distribution } \\
\text { (food fair) }\end{array}$ & $\begin{array}{l}\text { Collect } \\
\text { midterm } \\
\text { data }\end{array}$ & \\
\hline & & & & & & & & \multicolumn{5}{|c|}{ Monitor prices, security situation } \\
\hline \multirow[t]{2}{*}{2012} & & $\begin{array}{l}\text { Last cash } \\
\text { transfer } \\
\text { and } \\
\text { voucher } \\
\text { distribution } \\
\text { (food fair) }\end{array}$ & $\begin{array}{l}\text { Collect } \\
\text { final } \\
\text { data }\end{array}$ & & & & & & & & & \\
\hline & \multicolumn{3}{|c|}{$\begin{array}{c}\text { Monitor prices, security } \\
\text { situation }\end{array}$} & & & & & & & & & \\
\hline
\end{tabular}


Figure 3. Individual Choices Before and After Receiving an Unconditional Cash Transfer or Food Voucher

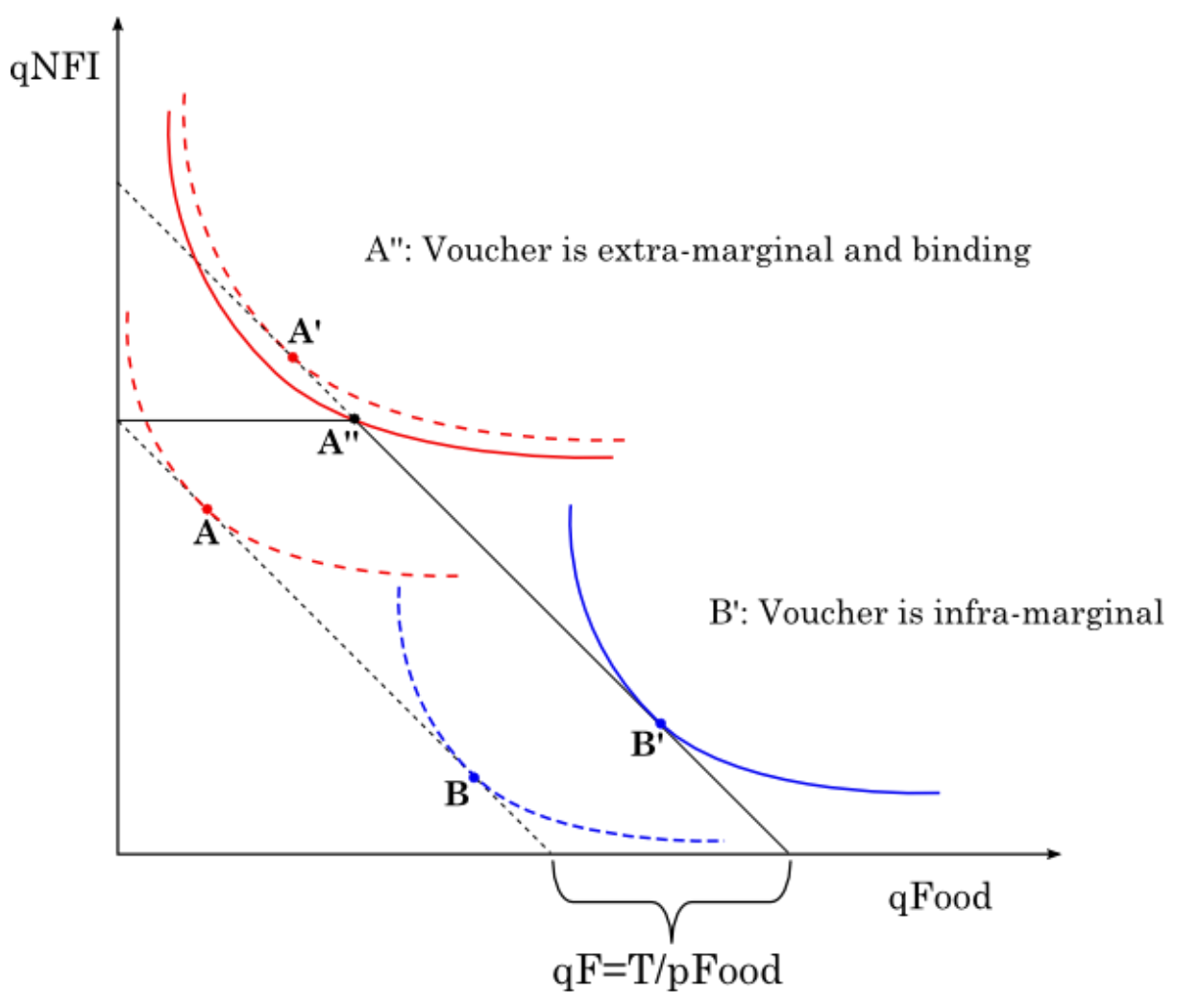

Notes: Modified from Cunha (2012) and Currie and Gahvari (2008). 
Figure 4. Extra-Marginality of the Voucher

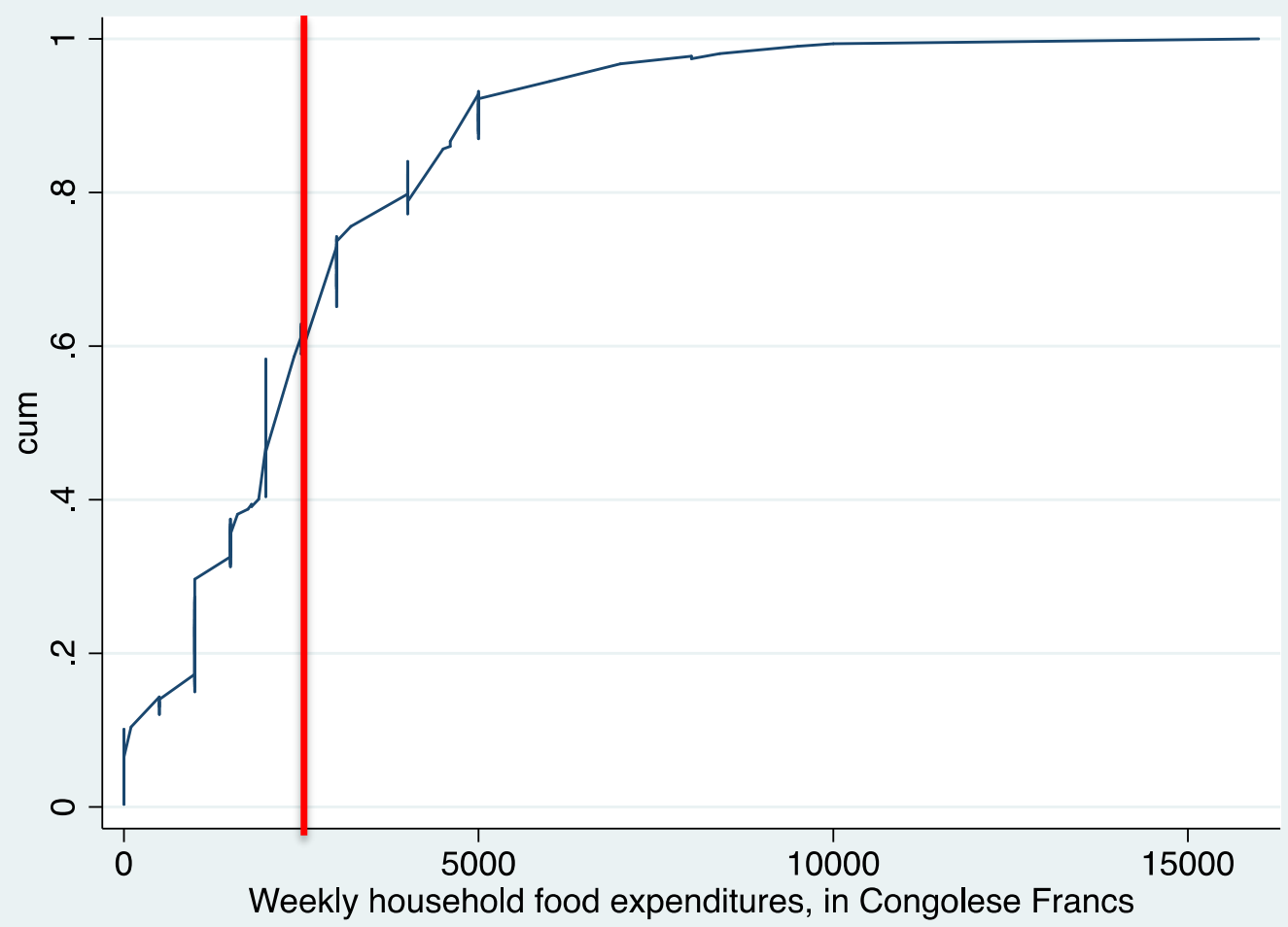

Notes: This figure shows the cumulative density function of weekly household food expenditures (pre-transfer) for the cash transfer group. The red line shows the average value of the transfer for the last two transfers (which could only be spent on food items). 
Figure 5. Uses of the Transfer by Transfer Modality

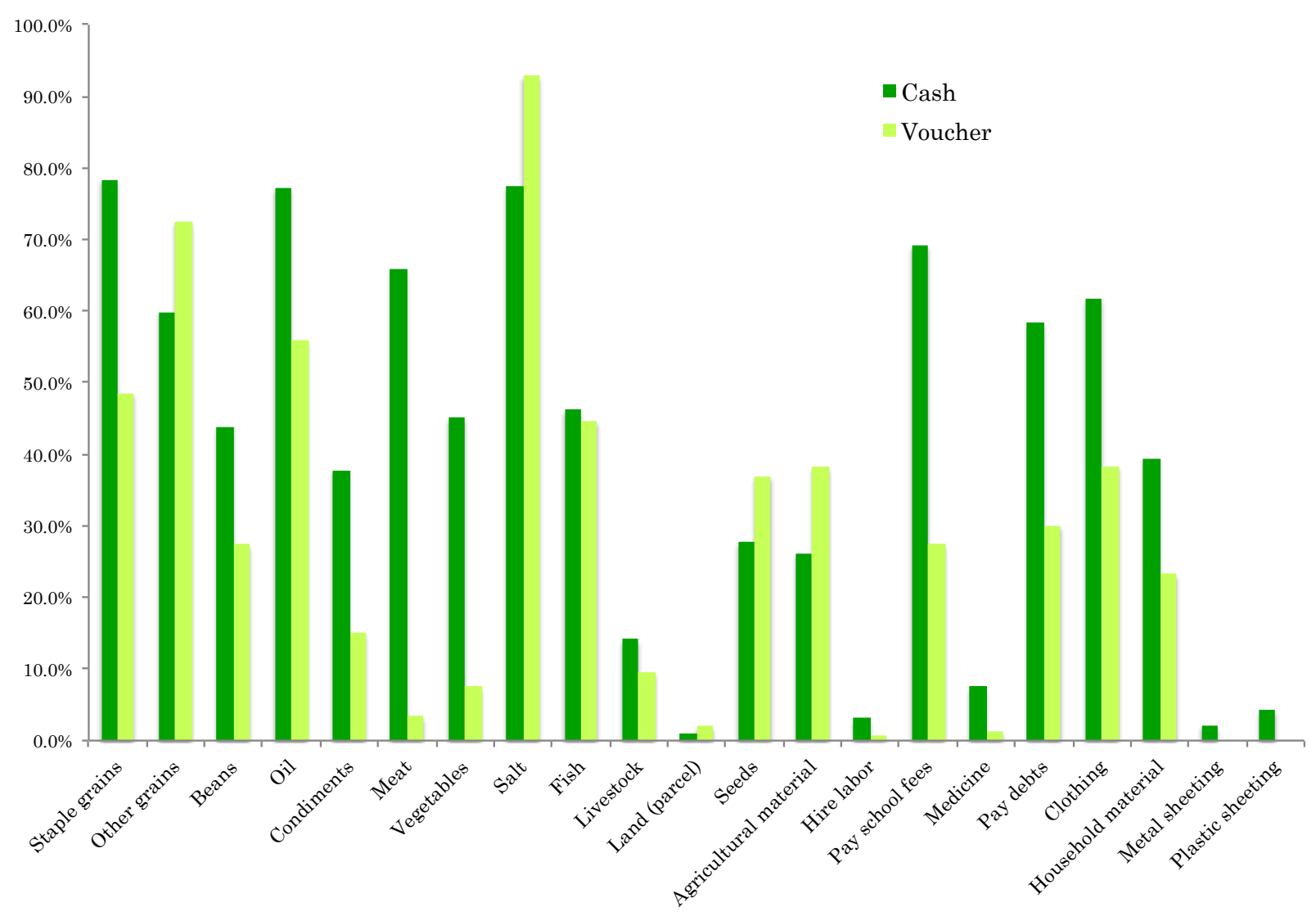

Notes: This figure shows the extensive margin of the uses of the transfer by each transfer modality (cash or voucher) using pooled data from the November and March rounds. 
Figure 6. Cumulative distribution functions (CDFs) of quantities purchased of specific food items
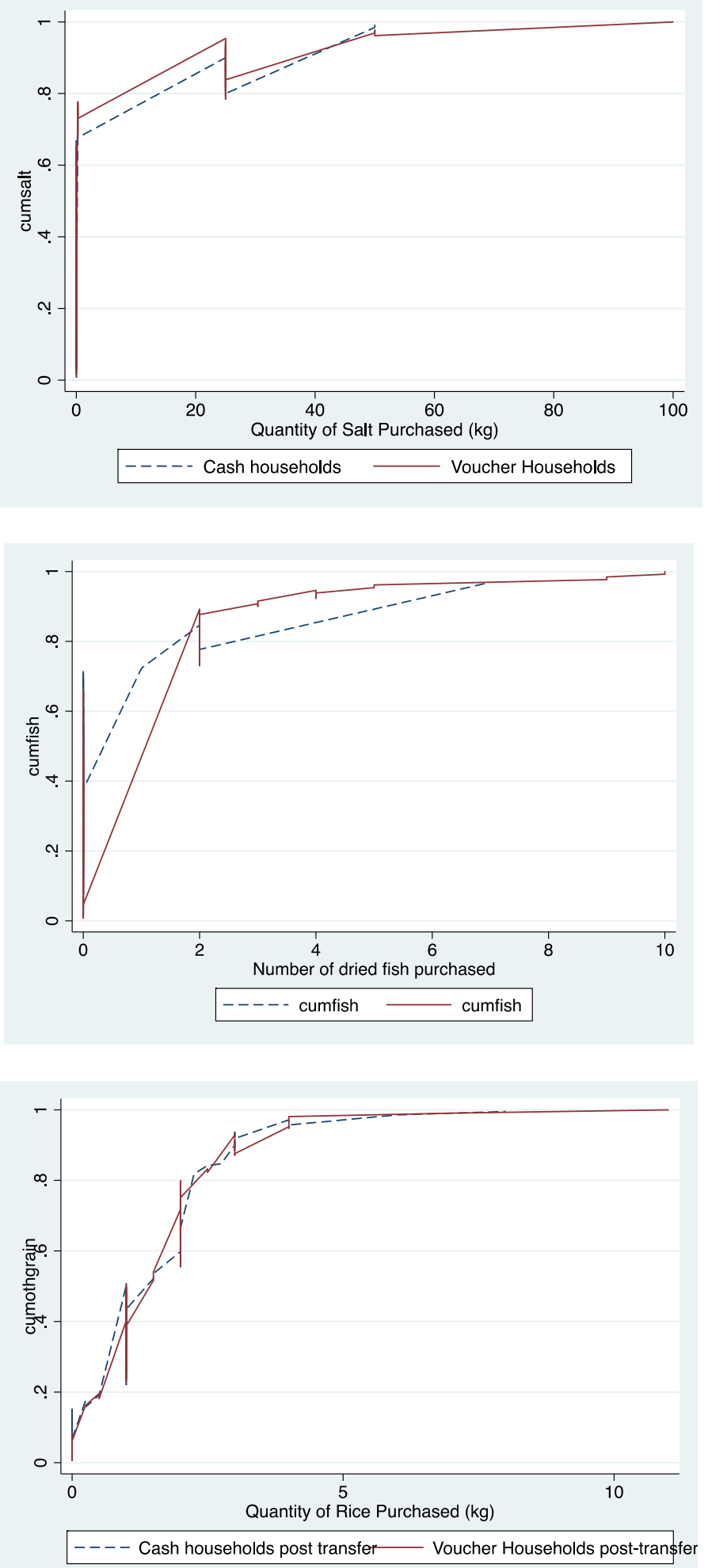
Figure 7. Costs (USD) per Recipient of the Cash Transfer versus Voucher

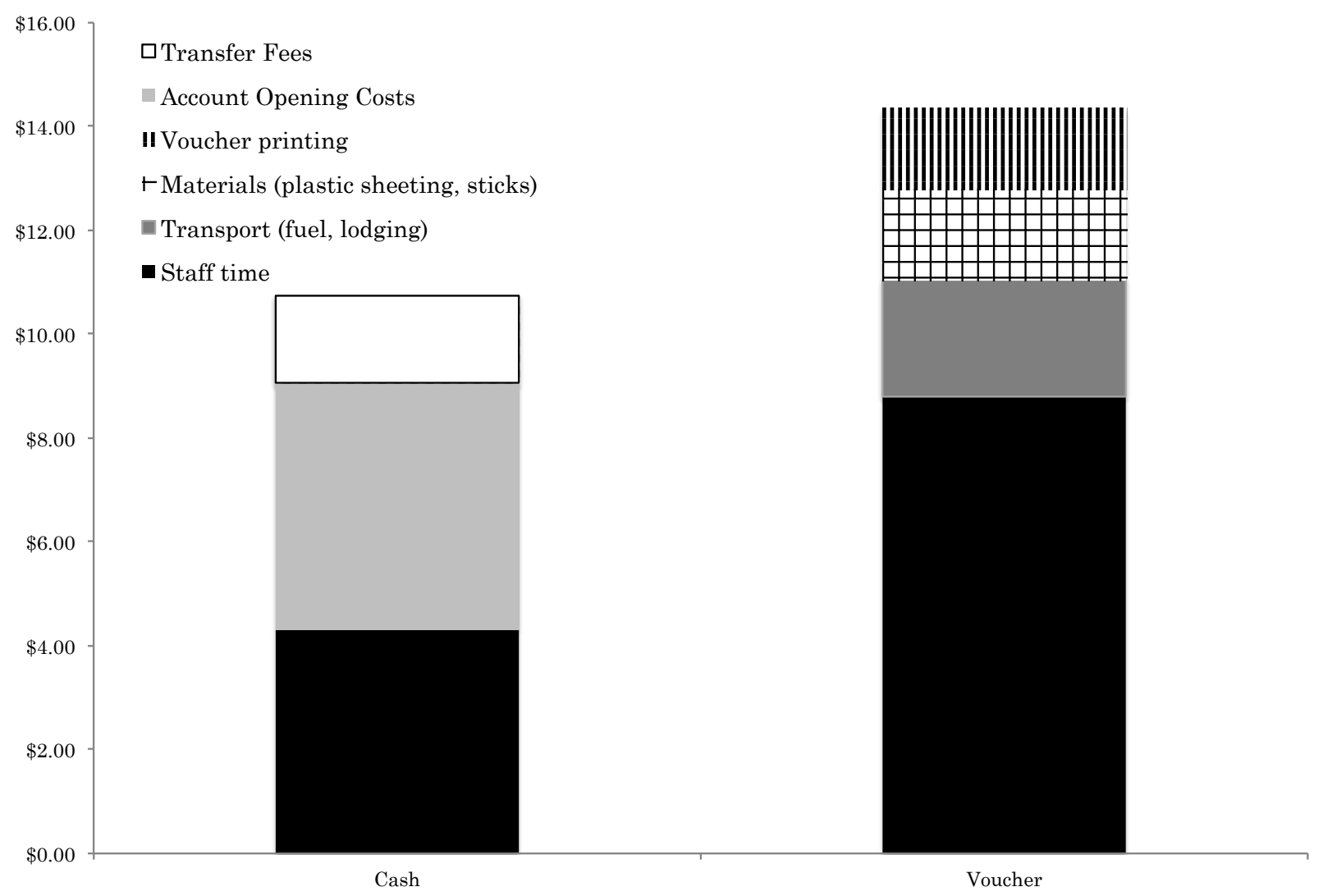


Table 1. Summary Statistics

\begin{tabular}{|c|c|c|c|c|c|}
\hline $\begin{array}{l}\text { Variable } \\
\end{array}$ & Obs & Mean & Std. Dev. & Min & $\operatorname{Max}$ \\
\hline \multicolumn{6}{|l|}{ Panel A: Socio-Demographic Characteristics } \\
\hline Household size & 252 & 5.5 & 1.9 & 1 & 11 \\
\hline Female-headed household & 252 & $42 \%$ & 0.5 & 0 & 1 \\
\hline \multicolumn{6}{|l|}{ Panel B: Income Sources } \\
\hline Number of income sources & 252 & 2.8 & 0.86 & 1 & 6 \\
\hline Daily agricultural salaried work & 252 & $58 \%$ & 0.49 & 0 & 1 \\
\hline Daily salaried work (other) & 252 & $78 \%$ & 0.41 & 0 & 1 \\
\hline Trade & 252 & $6 \%$ & 0.23 & 0 & 1 \\
\hline Agricultural production & 252 & $6 \%$ & 0.23 & 0 & 1 \\
\hline Searching forfuelwood & 252 & $2 \%$ & 0.13 & 0 & 1 \\
\hline Found work outside of DRC & 252 & $1 \%$ & 0.09 & 0 & 1 \\
\hline Total revenue earned during the past week & 252 & 2.44 & 4.72 & 0 & 50.6 \\
\hline Part of revenue used for food from the past week & 252 & 1.82 & 3.33 & 0 & 48 \\
\hline \multicolumn{6}{|l|}{ Panel C: Agricultural Production } \\
\hline Cultivated crops during last agricultural season & 251 & $10 \%$ & 0.29 & 0 & 1 \\
\hline$\#$ of plots used for cultivation & 252 & 0.13 & 0.45 & 0 & 4 \\
\hline Raised animals in the past year & 252 & $4 \%$ & 0.19 & 0 & 1 \\
\hline \multicolumn{6}{|l|}{ Types of animals raised: } \\
\hline Cows & 252 & $0 \%$ & 0.00 & 0 & 0 \\
\hline Goats & 252 & $1 \%$ & 0.09 & 0 & 1 \\
\hline Sheep & 252 & $0 \%$ & 0.00 & 0 & 0 \\
\hline Poultry & 252 & $3 \%$ & 0.16 & 0 & 1 \\
\hline Rabbit & 252 & $0 \%$ & 0.00 & 0 & 0 \\
\hline Produced animal by-products & 252 & $0 \%$ & 0.00 & 0 & 0 \\
\hline \multicolumn{6}{|l|}{ Panel D: Asset Ownership } \\
\hline Number of durable asset categories owned & 252 & 0.01 & 0.09 & 0 & 1 \\
\hline Number of non-durable asset categories owned & 252 & 10.98 & 3.53 & 2 & 22 \\
\hline Household owns mobile phone & 252 & $1 \%$ & 0.101 & 0 & 1 \\
\hline Household owns flashlight & 251 & $12 \%$ & 0.33 & 0 & 1 \\
\hline \multicolumn{6}{|l|}{ Panel E: Social Capital } \\
\hline Member of a community group & 252 & $20 \%$ & 0.431 & 0 & 2 \\
\hline \multicolumn{6}{|l|}{ Panel F: Food Security } \\
\hline Household diet diversity score (out of 12) & 252 & 2.9 & 1.75 & 0 & 9 \\
\hline Household has experienced food insecurity since June 2011 & 250 & $99 \%$ & 0.089 & 0 & 1 \\
\hline Number of meals eaten in the past 24 hours & 252 & 1.29 & 0.53 & 0 & 3 \\
\hline Number of meals eaten by children in the past 24 hours & 252 & 1.29 & 0.54 & 0 & 3 \\
\hline
\end{tabular}


Table 2. Comparison of Pre-Program Characteris tics

| Panel A: Socio-Demographic Characteristics

Household size

Number of children (less than 15 years of age)

Program recipient is female

Program recipient is married

Program recipient is widowed

Program recipient has some education

Program recipient born in Masisi Territory

Living in camp for more than one year
Voucher

Part of revenue used for food from the past week

\section{Panel C: Agricultural Production and Livestock}

Had access to land

Owned poultry

Panel D: Asset Ownership

Total value of household assets

Number of durable goods categories owned

Number of non-durable goods categories owned

\section{Panel E: Food Security}

Household diet diversity score (out of 12)

Number of meals in last day (household

2.78
Mean

(s.d.)

5.56

3.22

0.96

0.69

0.21

0.49

0.88

0.68

1.83

1.74

24.92

17.30

18.94

Cash Difference

Mean (s.d.) Coeff (s.e.)

5.38

0.18

(0.24)

0.01

(0.22)

$-0.03$

$(0.03)$

$-0.09$

(0.07)

0.07

(0.06)

$-0.03$

(0.09)

$-0.09 * *$

(0.04)

$-0.12$

(0.08)

0.08

(0.11)

0.90

(5.97)

$-1.64$

(4.05)

$-0.01$

$(0.02)$

0.03

$(0.02)$

$-2.14$

0.00

(0.01)

0.04

(0.45)

$\begin{array}{llc}11.00 & 10.96 & 0.04 \\ & & (0.45)\end{array}$

3.04

0.26

$(0.22)$

$\begin{array}{lll}1.29 & 1.28 & 0.01\end{array}$

(0.07) 
Number of meals eaten in last day (children)

Suffered from food insecurity since last harvest

0.99

0.99

$(0.07)$

Note: Durable asset categories include a bike, generator and storage facility. Non-durable asset categories include chairs, radios, mattresses, and utensils. 
Table 3: Uses of the Transfer (All Transfers)

Panel A: Food Items

Number of different purchases made (last transfer)

Staple grains (maize, maize flour)

Beans

Condiments

Oil

Meat

Vegetables

Salt

Fish
(1)

Voucher Mean (s.d.)

4.01

$(0.23)$

0.49

(0.04)

0.73

(0.04)

0.27

(0.04)

0.15

(0.03)

0.56

(0.04)

0.03

(0.02)

0.08

(0.02)

0.93

(0.03)

0.45

(0.05)

Panel B: Agricultural Items

Seeds

Hired labor

(0.04)

(0.06)
Livestock

Agricultural inputs

(2)

Cash

Coeff(s.e.)

$2.53 * * *$

(0.38)

$0.30 * * *$

(0.05)

$-0.13^{* *}$

(0.05)

$0.16^{* * *}$

(0.05)

$0.23^{* * *}$

(0.05)

$0.21 * * *$

(0.05)

$0.63^{* * * *}$

(0.04)

$0.38 * * *$

(0.04)

$-0.16 * * *$

$(0.05)$

0.02

$(0.08)$

$\begin{array}{cc}0.05 & 0.10 * * * \\ (0.04) & (0.02)\end{array}$

$0.37-0.09 *$

$(0.05)$

$0.38 \quad-0.12$

$(0.08)$

$0.01 \quad 0.02$

$(0.01)$

$(0.02)$

Panel C: Other Non-Food Items

Clothing

$\begin{array}{cc}0.38 & 0.23 * * * \\ (0.04) & (0.06)\end{array}$

Metal sheeting

$0 \quad 0.02$

$(0.00) \quad(0.02)$
0

Plastic sheeting

$0 \quad 0.04 * *$

$(0.00)$

$(0.02)$

Panel D: Education and Health Expenditures

School fees

$0.28 \quad 0.42 * * *$


Medicines

Reimburse debts

Observations

Notes: This table presents a simple difference comparison of households in the two treatments. Column 1 shows the mean and s.d. of the basic treatment (voucher) households, whereas Column 2 shows the difference between the cash transfer treatment and the voucher treatment. Heteroskedasticity-consistent s.e. are presented in parentheses. $* * *$ significant at the 1 percent level, ** significant at the 5 percent level, * significant at the 10 percent level. 
Table 4: Food Expenditures and Quantities Demanded of Specific Food Ite ms

(1)

Voucher

Panel A: Demand for Food

Household food expenditures (FC) in previous week

Ln(household food expenditures in previous week)

Percent of income spent on food

Salt $(\mathrm{kg})$

Rice $(\mathrm{kg})$

Fish (number)
Mean (s.d.)

$2,568.10$

(211.18)

7.67

83.62

(3.52)

12.34

(2.38)

1.69

(0.19)

1.75

(0.32)
Cash

Coeff(s.e.)

$-85.56$

(248.78)

0.008

(0.08)

$-2.53$

(4.26)

$-9.79 * * *$

(2.65)

$-0.34 *$

(0.20)

$-1.49 * * *$

(0.34)

Notes: This table presents a simple difference comparis on of households in the two treat ments. Column 1 shows the mean and s.d. of the basic treatment (voucher) households, whereas Column 2 shows the difference between the cash transfer treatment and the voucher treatment. Heteroskedasticity -consistent s.e. are presented in parentheses. *** significant at the 1 percent level, ** significant at the 5 percent level, * significant at the 10 percent level. 


\begin{tabular}{|c|c|c|c|}
\hline & $\begin{array}{c}(1) \\
\text { Baseline } \\
\text { Mean (s.d.) }\end{array}$ & $\begin{array}{c}(2) \\
\text { Voucher } \\
\text { Mean (s.d.) }\end{array}$ & $\begin{array}{c}\text { (3) } \\
\text { Cash } \\
\text { Coeff(s.e.) }\end{array}$ \\
\hline \multicolumn{4}{|l|}{ Panel A: Food Consumption } \\
\hline Household diet diversity (out of 12) & 2.90 & $\begin{array}{c}3.36 \\
(0.17)\end{array}$ & $\begin{array}{c}0.13 \\
(0.19)\end{array}$ \\
\hline Grains & 0.61 & $\begin{array}{c}0.85 \\
(0.09)\end{array}$ & $\begin{array}{l}-0.01 \\
(0.05)\end{array}$ \\
\hline Tubers & 0.73 & $\begin{array}{c}0.76 \\
(0.09)\end{array}$ & $\begin{array}{l}-0.00 \\
(0.05)\end{array}$ \\
\hline Beans & 0.14 & $\begin{array}{c}0.37 \\
(0.09)\end{array}$ & $\begin{array}{c}0.00 \\
(0.05)\end{array}$ \\
\hline Vegetables & 0.57 & $\begin{array}{c}0.56 \\
(0.10)\end{array}$ & $\begin{array}{c}0.02 \\
(0.06)\end{array}$ \\
\hline Fruits & 0.05 & $\begin{array}{c}0.01 \\
(0.03)\end{array}$ & $\begin{array}{l}-0.01 \\
(0.02)\end{array}$ \\
\hline Fats & 0.27 & $\begin{array}{c}0.64 \\
(0.10)\end{array}$ & $\begin{array}{c}0.07 \\
(0.06)\end{array}$ \\
\hline Eggs & 0.00 & $\begin{array}{l}-0.01 \\
(0.02)\end{array}$ & $\begin{array}{l}0.02 * \\
(0.01)\end{array}$ \\
\hline Milk & 0.00 & $\begin{array}{c}0.00 \\
(0.00)\end{array}$ & $\begin{array}{c}0.00 \\
(0.00)\end{array}$ \\
\hline Meat & 0.03 & $\begin{array}{c}0.09 \\
(0.03)\end{array}$ & $\begin{array}{c}0.01 \\
(0.03)\end{array}$ \\
\hline Fish & 0.27 & $\begin{array}{c}0.18 \\
(0.04)\end{array}$ & $\begin{array}{c}0.05 \\
(0.04)\end{array}$ \\
\hline Condiments & 0.01 & $\begin{array}{l}-0.00 \\
(0.02) \\
\end{array}$ & $\begin{array}{l}-0.00 \\
(0.01) \\
\end{array}$ \\
\hline \multicolumn{4}{|l|}{ Panel B: Other Measures of Food Security } \\
\hline Number of meals per day (household) & 1.29 & $\begin{array}{c}1.46 \\
(0.06)\end{array}$ & $\begin{array}{l}-0.00 \\
(0.07)\end{array}$ \\
\hline Number of meals per day (children) & 1.29 & $\begin{array}{c}1.71 \\
(0.19)\end{array}$ & $\begin{array}{l}-0.31 \\
(0.32)\end{array}$ \\
\hline Suffered from food insecurity since previous harvest & .99 & $\begin{array}{c}0.73 \\
(0.07)\end{array}$ & $\begin{array}{l}-0.10 \\
(0.09)\end{array}$ \\
\hline Months of adequate household food provisioning & 1.69 & $\begin{array}{c}2.27 \\
(0.07) \\
\end{array}$ & $\begin{array}{c}0.10 \\
(0.09) \\
\end{array}$ \\
\hline $\begin{array}{l}\text { Notes: This table presents a simple difference comparison o } \\
\text { the mean and s.d. of the basic treatment (voucher) househol } \\
\text { cash transfer treatment and the vouchertreatment. Heteros } \\
* * * \text { significant at the } 1 \text { percent level, } * * \text { significant at the } 5\end{array}$ & $\begin{array}{l}\text { eholds in the ty } \\
\text { ereas Column } \\
\text { city-consisten } \\
\text { t level, * signi }\end{array}$ & $\begin{array}{l}\text { eatments. Cc } \\
\text { ows the differ } \\
\text { are presentec } \\
\text { at at the } 10 \mathrm{pe}\end{array}$ & $\begin{array}{l}\text { an } 1 \text { shows } \\
\text { e between the } \\
\text { parentheses. } \\
\text { nt level. }\end{array}$ \\
\hline
\end{tabular}




\begin{tabular}{|c|c|c|c|}
\hline & $\begin{array}{c}(1) \\
\text { Base line } \\
\text { Mean (s.d.) }\end{array}$ & $\begin{array}{c}(2) \\
\text { Voucher } \\
\text { Mean (s.d.) }\end{array}$ & $\begin{array}{c}(3) \\
\text { Cash } \\
\text { Coeff(s.e.) }\end{array}$ \\
\hline \multicolumn{4}{|l|}{ Panel A: Income and Assets Ownership } \\
\hline Income in the previous week & 1.01 & $\begin{array}{c}3.40 \\
(0.54)\end{array}$ & $\begin{array}{c}1.01 \\
(0.77)\end{array}$ \\
\hline $\log ($ Household income in previous week) & & 7.95 & $\begin{array}{c}0.11 \\
(0.10)\end{array}$ \\
\hline Money left from transfer & & $\begin{array}{c}0.01 \\
(0.02)\end{array}$ & $\begin{array}{c}0.09 * * * \\
(0.02)\end{array}$ \\
\hline Amount of money remaining (savings) & 0 & $\begin{array}{l}11.32 \\
(4.25)\end{array}$ & $\begin{array}{c}1.56 * * * \\
(0.59)\end{array}$ \\
\hline Number of income sources & 2.8 & $\begin{array}{c}1.7 \\
(0.09)\end{array}$ & $\begin{array}{c}0.03 \\
(0.10)\end{array}$ \\
\hline Total value of household assets (USD) & 61.72 & $\begin{array}{l}71.72 \\
(4.49)\end{array}$ & $\begin{array}{l}-3.41 \\
(4.25)\end{array}$ \\
\hline Log (value of household assets) & & 4.05 & $\begin{array}{l}-0.02 \\
(0.06)\end{array}$ \\
\hline Number of durable assets owned & 0.01 & $\begin{array}{c}0.04 \\
(0.02)\end{array}$ & $\begin{array}{l}-0.00 \\
(0.01)\end{array}$ \\
\hline Number of non-durable assets owned & 10.98 & $\begin{array}{c}11.6 \\
(0.54)\end{array}$ & $\begin{array}{l}-0.12 \\
(0.65)\end{array}$ \\
\hline Plastic sheeting & 0.42 & $\begin{array}{c}0.31 \\
(0.05)\end{array}$ & $\begin{array}{l}-0.08 \\
(0.05)\end{array}$ \\
\hline Metal sheeting & 0.00 & $\begin{array}{c}0.09 \\
(0.03)\end{array}$ & $\begin{array}{l}-0.03 \\
(0.03)\end{array}$ \\
\hline Hoe & 0.23 & $\begin{array}{c}0.4 \\
(0.05)\end{array}$ & $\begin{array}{c}-0.13 * * \\
(0.05)\end{array}$ \\
\hline Axe & 0.16 & $\begin{array}{c}0.27 \\
(0.05) \\
\end{array}$ & $\begin{array}{l}-0.04 \\
(0.05) \\
\end{array}$ \\
\hline \multicolumn{4}{|l|}{ Panel B: Land and Livestock Ownership } \\
\hline Own land & 0.02 & $\begin{array}{c}0.04 \\
(0.02)\end{array}$ & $\begin{array}{c}0.01 \\
(0.03)\end{array}$ \\
\hline Practice livestock & 0.04 & $\begin{array}{c}0.24 \\
(0.04)\end{array}$ & $\begin{array}{l}-0.02 \\
(0.04)\end{array}$ \\
\hline Number of livestock categories owned & 0.04 & 0.24 & $\begin{array}{l}-0.02 \\
(0.04)\end{array}$ \\
\hline Own poultry & 0.03 & $\begin{array}{c}0.24 \\
(0.04)\end{array}$ & $\begin{array}{l}-0.05 \\
(0.04)\end{array}$ \\
\hline Own rabbits & 0.00 & 0.01 & 0.02 \\
\hline
\end{tabular}


$(0.02)$

\section{Panel C: Coping Strategies}

One household member migrated

$\begin{array}{lll}0.04 & 0.02 & 0.04 *\end{array}$

Sold household goods

0.11

$(0.01)$

$(0.02)$

Sold agricultural tools

0.04

0.03

$-0.02 *$

Sold agricultural tools

$(0.02)$

$(0.01)$

0.01

$-0.01$

Reduced number of meals per day

0.52

$(0.01)$

$(0.01)$

0.25

$-0.01$

Took children out of school

0.16

(0.05)

(0.06)

0.05

$-0.03$

(0.02)

(0.02)

Notes: This table presents a simple difference comparison of households in the two treatments. Column 1 shows the mean and s.d. of the basic treatment (voucher) households, whereas Column 2 shows the difference between the cash transfer treatment and the voucher treatment. Heteroskedasticity-consistent s.e. are presented in parentheses. *** significant at the 1 percent level, ** significant at the 5 percent level, * significant at the 10 percent level. 


\begin{tabular}{|c|c|c|}
\hline & $\begin{array}{c}(1) \\
\text { Voucher } \\
\text { Mean (s.d.) }\end{array}$ & $\begin{array}{c}(2) \\
\text { Cash } \\
\text { Coeff(s.e.) }\end{array}$ \\
\hline \multicolumn{3}{|l|}{ Panel A: Location of Purchases } \\
\hline Boutique in camp & $\begin{array}{c}0.01 \\
(0.01)\end{array}$ & $\begin{array}{l}-0.00 \\
(0.01)\end{array}$ \\
\hline Market outside camp & $\begin{array}{c}0.02 \\
(0.02)\end{array}$ & $\begin{array}{c}0.97 * * * \\
(0.01)\end{array}$ \\
\hline Masisi Center market (20 km from camp) & $\begin{array}{c}0.00 \\
(0.00)\end{array}$ & $\begin{array}{c}0.51 * * * \\
(0.05)\end{array}$ \\
\hline Nyabiondo market (2 kmfrom camp) & $\begin{array}{c}0.00 \\
(0.00)\end{array}$ & $\begin{array}{c}0.45 * * * \\
(0.05)\end{array}$ \\
\hline Hospital & $\begin{array}{c}0.00 \\
(0.00)\end{array}$ & $\begin{array}{c}0.01 \\
(0.01)\end{array}$ \\
\hline Voucher fair & $\begin{array}{c}0.99 \\
(0.01)\end{array}$ & $\begin{array}{c}-0.99 * * * \\
(0.01)\end{array}$ \\
\hline School & $\begin{array}{c}0.00 \\
(0.00) \\
\end{array}$ & $\begin{array}{l}0.03^{*} \\
(0.02) \\
\end{array}$ \\
\hline \multicolumn{3}{|l|}{ Panel B: Timing of Purchases } \\
\hline Save part of transfer & $\begin{array}{c}0.00 \\
(0.00)\end{array}$ & $\begin{array}{c}0.09 * * * \\
(0.02)\end{array}$ \\
\hline Spent money in more than one purchase & $\begin{array}{c}0.00 \\
(0.03) \\
\end{array}$ & $\begin{array}{c}0.74 * * * \\
(0.04)\end{array}$ \\
\hline \multicolumn{3}{|c|}{ Panel C: Intra-Household Decision-Making with Respect to Transfers } \\
\hline Beneficiary responsible for spending all or part of transfer & $\begin{array}{c}0.94 \\
(0.02)\end{array}$ & $\begin{array}{l}-0.03 \\
(0.03)\end{array}$ \\
\hline Husband responsible for spending transfer & $\begin{array}{c}0.46 \\
(0.05)\end{array}$ & $\begin{array}{l}-0.06 \\
(0.06)\end{array}$ \\
\hline No one else responsible for spending transfer & $\begin{array}{c}0.06 \\
(0.02)\end{array}$ & $\begin{array}{l}-0.02 \\
(0.03)\end{array}$ \\
\hline Discussed how to use transfer in advance with other person & 0.85 & -0.02 \\
\hline
\end{tabular}

Notes: This table presents a simple difference comparis on of households in the two treatments. Column 1 shows the mean and s.d. of the basic treatment (voucher) households, whereas Column 2 shows the difference between the cash transfer treatment and the voucher treatment. Heteroskedasticity-consistent s.e. are presented in parentheses. $* * *$ significant at the 1 percent level, ** significant at the 5 percent level, * significant at the 10 percent level. 
(1)

Voucher

Mean (s.d.)

Panel A: Transfers are Non-Binding

Program recipient shared part of money received

Program recipient shared part of goods purchased
0.25

0.46

(0.04)
(2)

Cash

Coeff(s.e.)

$0.15 * * *$

$-0.14 * *$

\section{Panel B: Voucher sales}

Amount of transfer spent (USD)

63.53

$5.20 *$

(2.67)

Panel C: Intra-Household Decision-Making with Respect to Transfers

Husband makes education decisions alone

$$
0.3
$$

Husband makes agriculture decisions alone

Husband decides whether to share with other households alone

0.16

Husband decides whether/how to save alone

0.3

0.01

Ratio of women to men's clothing

$(0.25)$

Notes: This table presents a simple difference comparis on of households in the two treatments. Column 1 shows the mean and s.d. of the basic treatment (voucher) households, whereas Column 2 shows the difference between the cash transfer treatment and the voucher treatment. Heteroskedasticity-consistent s.e. are presented in parentheses. $* * *$ significant at the 1 percent level, $* *$ significant at the 5 percent level, * significant at the 10 percent level. 
Table 9: Alternative Explanations

\begin{tabular}{lcc}
\hline \hline & $(1)$ & $(2)$ \\
Voucher & Cash \\
Cean (s.d.) & Coeff(s.e.) \\
Panel A: Take Up and Leakage & 1.00 & 0.00 \\
Received transfer & $(0.00)$ & $(0.00)$ \\
Number of transfers received & 2.98 & -0.02 \\
Amount received (all transfers) & $(0.03)$ & $(0.01)$ \\
& $99,807.42$ & 485.37 \\
Amount received (second transfer) & $(548.61)$ & $(336.42)$ \\
& $18,352.54$ & 26.87 \\
\hline Panel B: Attrition & $(167.97)$ & $(168.29)$ \\
Attrition November 2011 & & \\
Attrition March 2012 & 0.46 & -0.03 \\
& & $(0.06)$ \\
\hline Panel C: Illness and Death & 0.92 & 0.03 \\
Affected by conflict & & $(0.06)$ \\
Household member affected by illness & & \\
Household member died & 0.54 & -0.06 \\
& $(0.05)$ & 0.07 \\
\hline
\end{tabular}

Notes: This table presents a simple difference comparis on of households in the two treatments. Column 1 shows the mean and s.d. of the basic treatment (voucher) households, whereas Column 2 shows the difference between the cash transfer treatment and the voucher treatment. Heteroskedasticity-consistent s.e. are presented in parentheses. *** significant at the 1 percent level, ** significant at the 5 percent level, * significant at the 10 percent level. 